\title{
Unraveling human adult hippocampal neurogenesis
}

\author{
Miguel Flor-García ${ }^{1,2,5}$, Julia Terreros-Roncal ${ }^{1,3,5}$, Elena P. Moreno-Jiménez ${ }^{1,2,5}$, Jesús Ávila ${ }^{1,3}$, \\ Alberto Rábano ${ }^{4}$ and María Llorens-Martín $\circledast^{1,2,3^{\star}}$
}

Adult neurogenesis occurs in a few selected regions of the mammalian brain. One such region is the hippocampus, the socalled gateway to memory, where adult hippocampal neurogenesis (AHN) occurs. Here, we provide a comprehensive description of the methods used in our laboratory to unambiguously detect a population of immature neurons in the human hippocampus until the 10th decade of life. The criteria used to refine and develop the current protocol include obtaining post-mortem human samples of remarkable quality and under tightly controlled conditions for immunohistochemistry (IHC) studies, optimizing tissue processing and histological procedures, establishing criteria to reliably validate antibody signal and performing unbiased stereological cell counts. Moreover, we provide a detailed description of the parameters that, in our view, should be reported in human AHN studies. The opposing results obtained by introducing slight variations in the methodological conditions should be considered by future studies that seek to increase our knowledge of this fascinating process. By applying simple and inexpensive tissue pre-treatments, this protocol, which can be completed in 7 days, might be applicable to a variety of IHC studies performed on other tissues of human (or animal) origin.

Introduction

The hippocampus plays a crucial role in learning and memory. Moreover, this structure hosts continuous addition of new neurons throughout the lifetime ${ }^{1-3}$. This process, named adult hippocampal neurogenesis (AHN), is a multi-stage, tightly regulated form of neural plasticity that is involved in hippocampal-dependent functions such as spatial memory and pattern separation ${ }^{4}$. After exiting the cell cycle, newly generated neurons subsequently go through distinct maturation stages before becoming fully mature ${ }^{5}$. Due to their special electrophysiological properties ${ }^{6}$ and local and distal innervation pattern ${ }^{7}$, these neurons contribute in a unique way to hippocampal trisynaptic circuits during the period of time in which they are immature ${ }^{7}$. Given that the hippocampus is one of the brain regions most affected in neurodegenerative diseases such as Alzheimer's disease ${ }^{8}$ and that patients with this disease exhibit a markedly reduced number of immature neurons in this structure, a greater understanding of the basic aspects of this singular process is expected to facilitate the development of therapeutic strategies to restore brain plasticity in Alzheimer's disease and other neurodegenerative diseases.

The occurrence of AHN in humans has been widely studied by means of immunohistochemistry (IHC), producing contradictory results, either supporting ${ }^{10-12}$ or questioning ${ }^{13,14}$ this phenomenon. The entire field of AHN research may therefore benefit from the delineation of a reliable method to study this process in the human brain. Here, we provide a comprehensive description of the methods used in our laboratory to detect a population of immature neurons in the human hippocampus in high quality post-mortem human brain samples until the 10th decade of life, both under physiological and pathological conditions ${ }^{9}$. We provide a tissue pre-processing protocol that ensures the suitability of these samples for the study of AHN by IHC plus a detailed protocol for free-floating IHC in human brain samples (Figs. 1 and 2). We hope that this straightforward protocol can serve as a robust starting point for other researchers working in the field of AHN and can contribute to future efforts to expand our knowledge of this fascinating process.

${ }^{1}$ Department of Molecular Neuropathology, Centro de Biología Molecular 'Severo Ochoa', CBMSO, CSIC-UAM, Madrid, Spain. ${ }^{2}$ Department of Molecular Biology, Faculty of Sciences, Universidad Autónoma de Madrid, Madrid, Spain. ${ }^{3}$ Center for Networked Biomedical Research on Neurodegenerative Diseases (CIBERNED), Madrid, Spain. ${ }^{4}$ Neuropathology Department, CIEN Foundation, Madrid, Spain. ${ }^{5}$ These authors contributed equally to this work as first author: Miguel Flor-García, Julia Terreros-Roncal, Elena P. Moreno-Jiménez. *e-mail: m.llorens@csic.es 

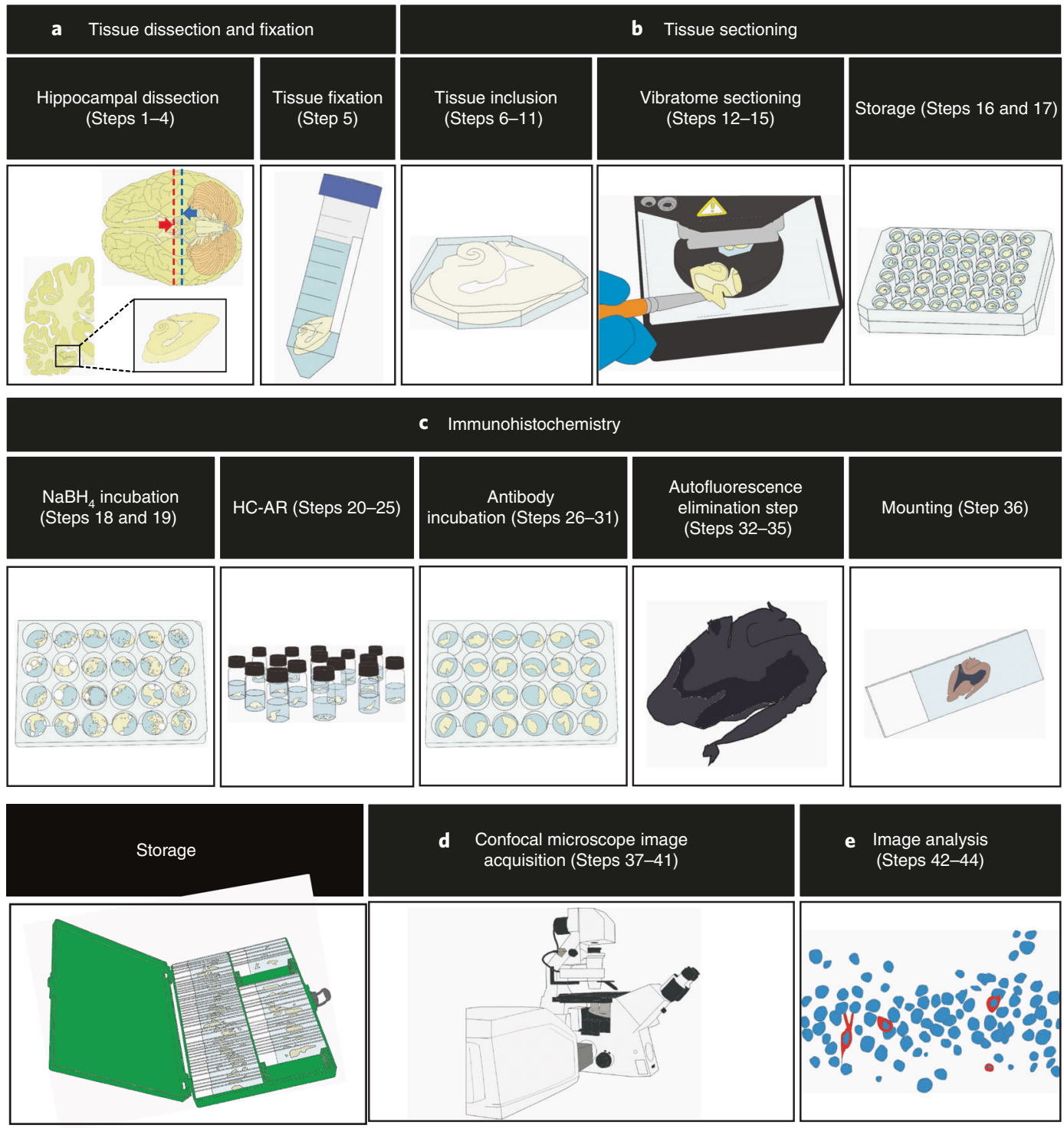

Fig. 1 | Experimental design. Briefly, post-mortem human brain samples are obtained from autopsies. (a) A small hippocampal fragment is dissected and rapidly immersed in fixative (freshly prepared $4 \%$ PFA) for $24 \mathrm{~h}$ at $4{ }^{\circ} \mathrm{C}$. After that time, the tissue is washed in $0.1 \mathrm{~N}$ PB and embedded in a $10 \%$ sucrose- $4 \%$ agarose solution to increase its robustness during tissue sectioning. (b) Brain samples are sectioned on a sliding blade vibratome. Sections are then stored at $-20{ }^{\circ} \mathrm{C}$ in a cryopreservative solution. (c) $\mathrm{IHC}$ includes performing two crucial steps prior to antibody incubation. The first step is incubation with a $0.5 \% \mathrm{NaBH}_{4}$ solution at rt. In the second step, sections are exposed to an $\mathrm{HC}-\mathrm{AR}$ protocol, which comprises the microwaving, water bath, and equilibration stages. After completing HC-AR, a free-floating IHC protocol is developed. After mounting sections and storing them protected from light, confocal immunofluorescence images are acquired in an LSM Zeiss800 confocal microscope (d). This is followed by stereological cell counts and analyses (e). In (a), the red arrow points to the posterior pole of the mammillary bodies, and the blue arrow points to the posterior pole of the uncus.

\section{Applications}

The protocol described here allows the reliable identification of numerous markers, in particular but not limited to those related to AHN, in post-mortem human brain tissue ${ }^{9}$. This protocol can be used as a general reference to obtain, process, and analyze good-quality human brain tissue for IHC studies. Moreover, we provide a comprehensive description not only of the procedures that, in our opinion, are necessary to validate an unknown antibody signal in human brain tissue, but also of the parameters that must be reported to increase data reproducibility between laboratories. This protocol is easily applicable to a variety of IHC studies performed on other tissues of human (or animal) origin. For instance, the methodology described allows both an enhancement of antibody-specific signal and a marked reduction of tissue autofluorescence (Figs. 3-5)-both issues commonly encountered in the study of human tissue ${ }^{15,16}$-by applying simple and inexpensive tissue pre-treatments. 

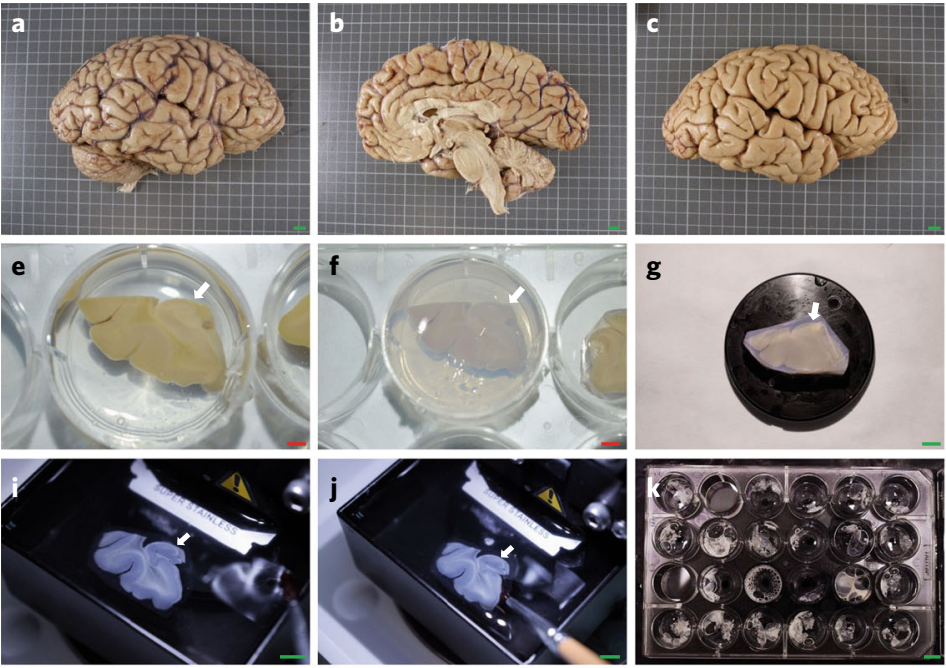

g
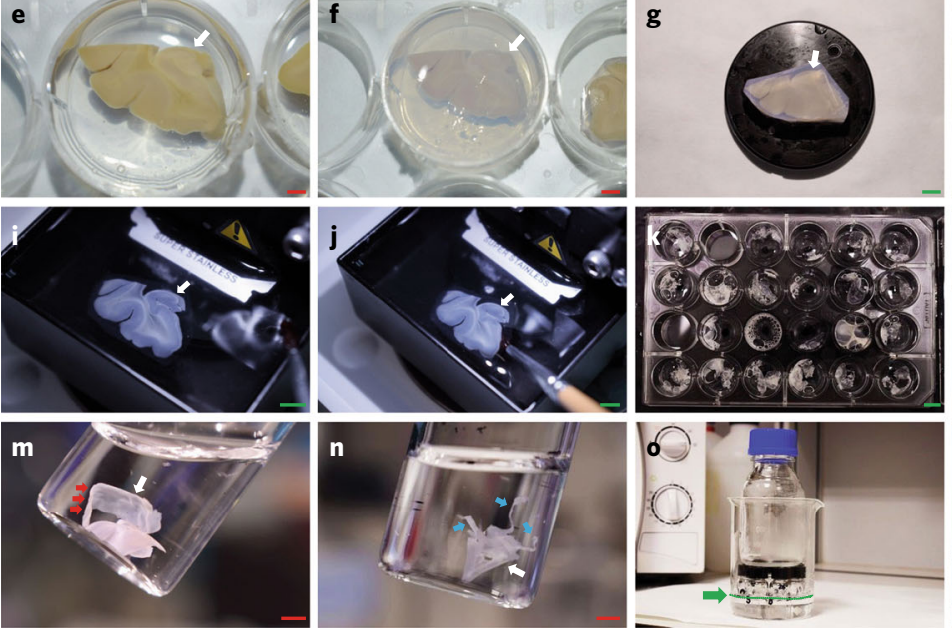
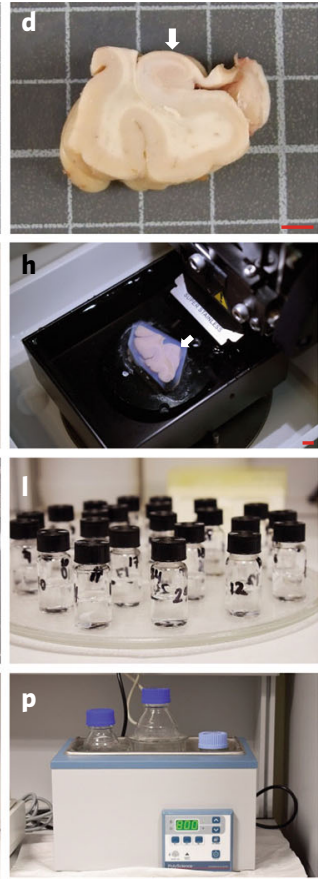

Fig. 2 | Experimental setup. (a-d) Obtaining brain tissue samples. (a) The whole brain is removed from the skull. (b) A sagittal interhemispheric incision serves to separate the two hemispheres. (c) Meninges are removed. (d) A 1-1.5$\mathrm{cm}$-thick block of the area of interest is dissected. The hippocampus is indicated with a white arrow. (e-j) Tissue sectioning on a sliding blade vibratome. (e) A liquid $10 \%$ sucrose- $4 \%$ agarose solution is poured inside an individual well of a multi-well plastic plate. The tissue block is immersed in the $10 \%$ sucrose- $4 \%$ agarose solution while it is still liquid. (f) After the complete solidification of the $10 \%$ sucrose- $4 \%$ agarose solution, it is no longer transparent. (g) A block of agarose should be sculpted, ensuring that $\geq 2 \mathrm{~mm}$ of agarose surround the tissue block in all the dimensions. The tissue block is fixed to the specimen holder using cyanoacrylate glue. (h) After cyanoacrylate solidification, the specimen holder is placed inside the vibratome tray, which should be filled with 0.1 N PB. (i) Sectioning parameters should be adjusted according to tissue robustness and characteristics. Sections covering the whole block should be obtained, and tissue damage should be avoided. (j) Sections are carefully collected with a soft brush and placed in a multi-well plate filled with cryoprotectant solution. (k-p) Tissue pre-treatment. (k) Sections are incubated with a $0.5 \% \mathrm{NaBH}_{4}$ solution in a multi-well plate. Abundant formation of bubbles is observed during this step. (I) Sections are placed inside scintillation vials filled with a citrate buffer antigen retrieval solution. ( $\mathbf{m}$ ) Sections are exposed to a variable number of microwave cycles inside the vials until a slight curvature of the borders of the sections, such as the one indicated with red arrows, is observed. (n) Excessive number or intensity of microwave cycles should be avoided to prevent tissue from tearing (indicated with blue arrows) during the microwave step. After this step, vials should be tightly closed and immersed in a water bath at $80^{\circ} \mathrm{C}$. (o) To prevent water from entering the scintillation vials, the vials are placed inside a large glass beaker filled with $80^{\circ} \mathrm{C}$ water. The amount of water in the outer glass beaker should remain at the level of the liquid inside the vials (indicated by a green arrow) to maintain a homogeneous temperature. Next, a heavy bottle is placed on top of the vials to increase their weight. (p) The whole set-up shown in (o) is then placed in the water bath at $80^{\circ} \mathrm{C}$. The level of water should remain below the top limit of the glass beaker to prevent water from entering the scintillation vials. White arrows indicate the location of the hippocampus throughout the procedure. Red arrows indicate the correct curvature of tissue borders that should be achieved after the microwaving step. Blue arrows indicate tissue damage caused by excessive intensity of the microwaving step. The green arrow and dashed line indicate the level of water that should be poured inside the glass beaker. Green scale bar: $1 \mathrm{~cm}$. Red scale bar: $0.5 \mathrm{~cm}$. Brain tissue donation, processing and use for research were in compliance with published protocols ${ }^{38}$, which include the obtaining of informed consent for brain tissue donation from living donors and the approval of the whole donation process by the Ethical Committee of the Banco de Tejidos CIEN (Committee Approval Reference \#15-20130110\#).

Moreover, our data not only show that slight variations in histological protocols markedly alter the capacity to detect markers of immature neurons in the human brain ${ }^{9}$, but also that distinct antibodies show dramatic variability in their IHC performance in human tissue, and that they are not equally sensitive to fixation or to variations in the histological procedure (Figs. 3-5). Thus, here we provide several guidelines for fine-tuning histological methods that may be useful for validating the signal of novel cell markers in other tissues of human origin. This protocol is intended to provide general recommendations on how to unambiguously identify cells that are positive for any potential cell marker in human samples. The guidelines provided herein aim to serve as a basis for establishing consensus criteria that might contribute to increasing data reproducibility between laboratories. 


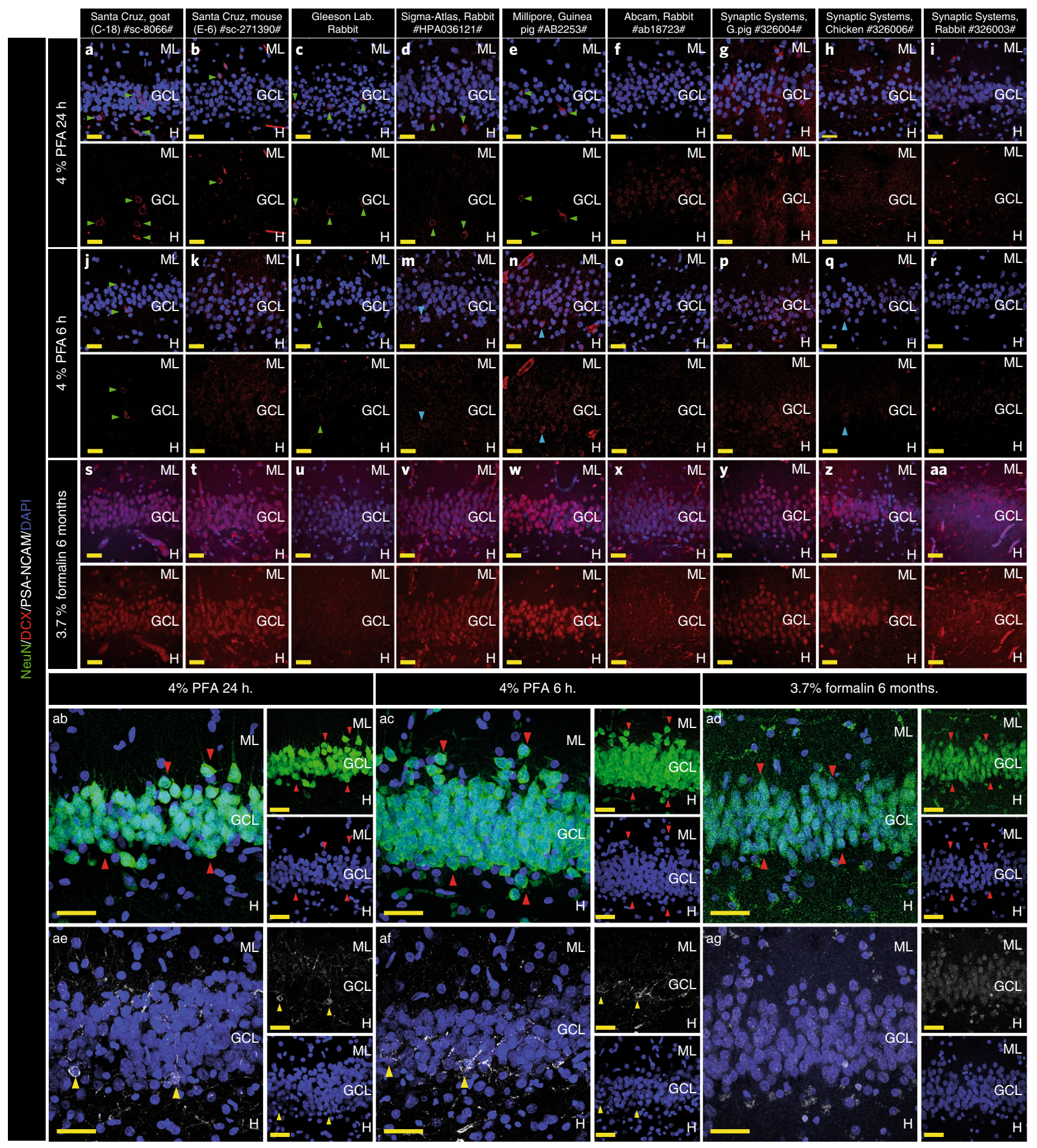

Comparison to alternative approaches

A range of methodologies have been used to address AHN in the human brain ${ }^{3,11,17-19}$. To date, only IHC and the recently developed RNAscope method (see below) have allowed spatial resolution at the single-cell level for the study of human $\mathrm{AHN}^{18}$. In contrast, and despite providing quantitative and robust data on protein expression, biochemical determinations, such as Western blot $^{20}$, are mostly devoid of the spatial resolution required. Identifying the cell populations (together with their morphological features) that express a given marker is vital for any developing field. Thus, techniques allowing the visualization of individual cells might be more helpful for addressing the puzzling question as to how a single immature cell survives and integrates into a pre-existing circuit in the adult human brain. 
4 Fig. 3 | Effect of fixation on the performance of different antibodies. (a-i) Staining with nine distinct anti-DCX antibodies on samples fixed for $24 \mathrm{~h}$ in $4 \%$ freshly prepared PFA. Note that only some of these antibodies (a-e) allow the unambiguous identification of $\mathrm{DCX}^{+}$cells with neuronal morphology (green triangles) in human tissue, whereas others render a high background and unspecific signal $(\mathbf{f}-\mathbf{i})$. (j-r) Staining with the same nine anti-DCX antibodies on samples fixed for $6 \mathrm{~h}$ in $4 \%$ freshly prepared PFA. Strikingly, antibodies show a different behavior to that observed on samples fixed for $24 \mathrm{~h}$ in the same fixative. In samples fixed for $6 \mathrm{~h}$, only some antibodies (a) and (c) display a robust signal and allow the unambiguous identification of $\mathrm{DCX}^{+}$cells (green triangles), whereas others specifically stain $\mathrm{DCX}^{+}$cells but exhibit a very weak signal (blue triangles) (d,e and $\mathbf{h}$ ). In contrast, other antibodies do not allow the identification of $D C X^{+}$cells $(\mathbf{b}, \mathbf{f}, \mathbf{g}$ and $\mathbf{i})$. (s-aa) Staining with the same nine anti-DCX antibodies on samples fixed in 3.7\% formalin for 6 months. Note that formalin fixation completely abolished the DCX signal for all the anti-DCX antibodies used and caused the appearance of an unspecific nuclear signal. (ab-ad) Staining with an anti-NeuN antibody on samples that had been fixed either in $4 \%$ freshly prepared PFA for 24 (ab) or 6 (ac) h, or in $3.7 \%$ formalin for 6 months (ad). Note that the NeuN-specific signal can be observed in the three fixation conditions. However, a substantial increase in the background is observed in samples fixed in formalin (ad). (ae-ag) Staining with an anti-polysialylated-neural cell adhesion molecule (PSA-NCAM) antibody on samples fixed either in 4\% freshly prepared PFA for 24 (ae) or 6 (af) h, or in $3.7 \%$ formalin for 6 months (ag). PSA-NCAM-specific signal and low background are observed in samples fixed in PFA (ae,af). In contrast, formalin fixation completely abolished the PSA-NCAM signal and caused the appearance of an unspecific nuclear signal (ag). As shown, the performance of each of the antibodies in this figure differs markedly in response to variations in fixation conditions. Thus, performing control fixation experiments is strongly recommended when a new antibody is intended to be tested on human tissue. Yellow scale bar: $50 \mu \mathrm{m}$. Green triangles: $\mathrm{DCX}^{+}$cells that show a robust signal. Blue triangles: $\mathrm{DCX}^{+}$cells that show a weak signal. Red triangles: $\mathrm{NeuN}^{+}$cells. Yellow triangles: PSA-NCAM ${ }^{+}$cells. Brain tissue donation, processing and use for research were in compliance with published protocols ${ }^{38}$, which include the obtaining of informed consent for brain tissue donation from living donors and the approval of the whole donation process by the Ethical Committee of the Banco de Tejidos CIEN (Committee Approval Reference \#15-20130110\#).

The first report supporting AHN in the human dentate gyrus (DG) was published by Peter Eriksson et al. in $1998^{3}$. These authors injected the thymidine analog 5-2'-bromo-deoxyuridine (BrdU) into a cohort of human subjects. This seminal study revealed the presence of double-labeled $\mathrm{BrdU}^{+}$/neuronal nuclei $(\mathrm{NeuN})^{+}$dentate granule cells (DGCs) in this brain structure. However, due to ethical limitations, BrdU administration is no longer permitted in human subjects. Nevertheless, an alternative methodology developed by the group headed by Jonás Frisén is also founded on a cell birthdating approach ${ }^{17,21}$, which is based on the incorporation of atmospheric ${ }^{14} \mathrm{C}$ during cell divi$\operatorname{sion}^{17}$. In 2007, an interesting approach based on the use of magnetic resonance spectroscopy was proposed by the group headed by Mirjana Maletic-Savatic ${ }^{19}$. This methodology was the first to raise the possibility of studying AHN in living human beings. Moreover, novel techniques such as RNAscope provide an alternative approach to simultaneously analyze the expression of various mRNAs in the same cell ${ }^{18}$. Despite the high potential of the data obtained from this methodology, it should be noted that it focuses on mRNA rather than on protein expression and it may still require complex validation procedures.

In contrast, most of the aforementioned techniques, together with the protocol described here, are based on the use of post-mortem samples of human origin. In this regard, numerous manuscripts describing various protocols for performing IHC to study AHN in human brain sections can be found in the literature ${ }^{10,11,13,14}$. Here we provide a detailed description of the methods used in our laboratory to analyze the expression of numerous validated proteins in the human hippocampus (Table 1). After exhaustive refinement of our previous protocols, the methodology we described here has allowed us to identify thousands of immature neurons in the human DG up to the 10th decade of life ${ }^{9}$. Given that antibodies show variable performance and sensitivity to variations in histological procedures (Figs. 3-5), it should be considered that other methods may allow similar (or even better) performance of certain antibodies. Researchers are strongly encouraged to compare the protocol described here with the standard histological methods used in their respective laboratories, as the characteristics of the brain samples may critically determine the most adequate method for their purposes. Moreover, consideration should be given to the need to combine as many different methodologies as are available to increase our current knowledge of the process of $\mathrm{AHN}$ in the human brain.

\section{Limitations and optimization}

Given that standard procedures followed at brain banks worldwide include sample fixation in formalin for prolonged periods, the main limitation of the present protocol is the reduced number of human brain samples processed as described herein. Therefore, due consideration should be given to 


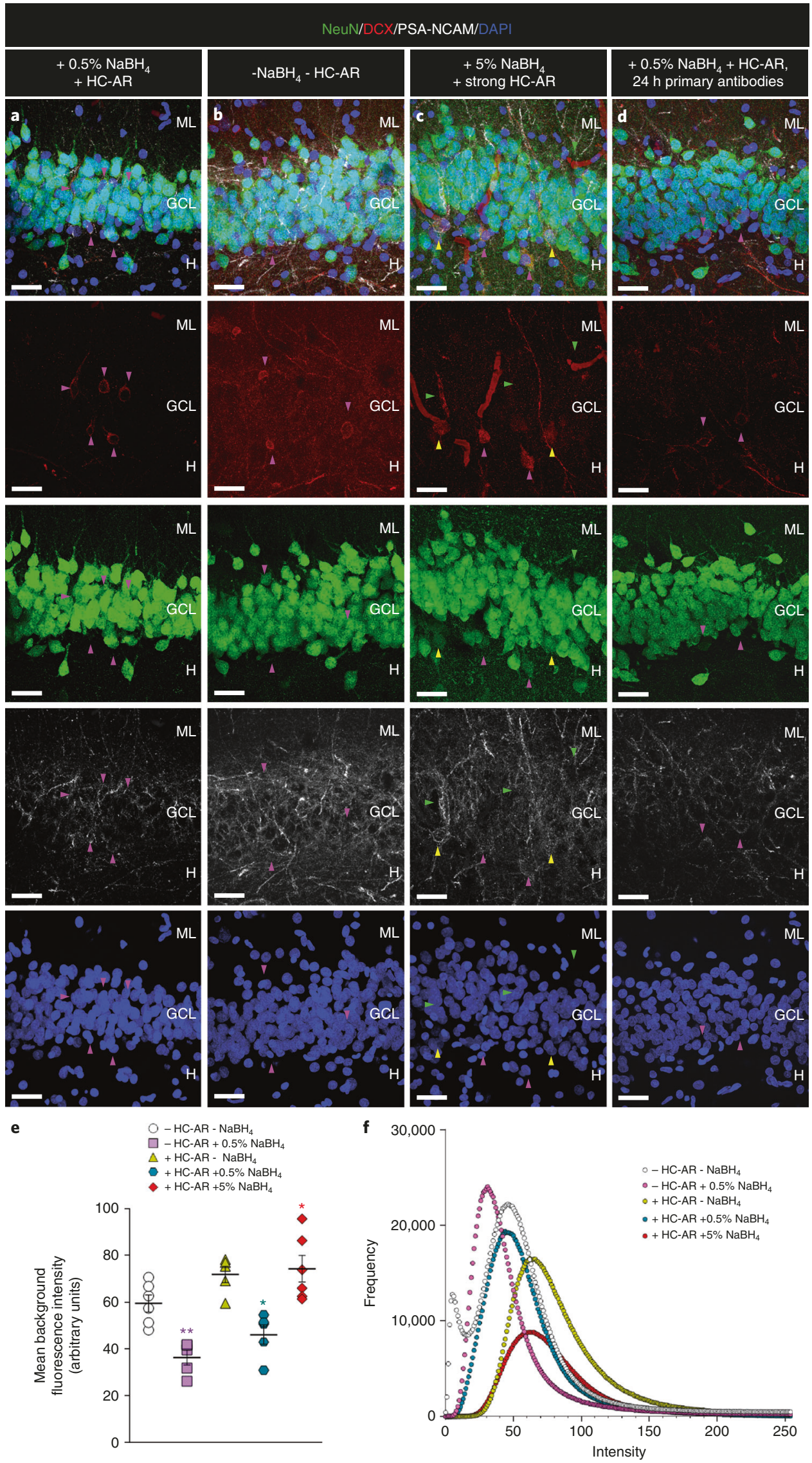


4 Fig. 4 | Effects of variations in the histological procedures on staining with different antibodies in samples fixed in 4\% PFA for $24 \mathrm{~h}$ at $4{ }^{\circ} \mathrm{C}$. (a) Staining with anti-DCX, anti-PSA-NCAM and anti-NeuN antibodies (5-day primary antibody incubation) after sample incubation with a $0.5 \% \mathrm{NaBH}_{4}$ solution and standard-intensity HC-AR. The three antibodies are seen to show good signal selectivity under these conditions. DCX ${ }^{+}$cells can be unambiguously identified on the basis of morphologic criteria (magenta triangles). Low background intensity is observed in the three channels. (b) Staining with anti-DCX, anti-PSA-NCAM and anti-NeuN antibodies (5-day primary antibody incubation) in the absence of $\mathrm{NaBH}_{4}$ incubation and $\mathrm{HC}-\mathrm{AR}$. Although some $\mathrm{DCX}{ }^{+}$cells (magenta triangles) can be identified, the background is outstanding in the red and white channels. In contrast, NeuN shows acceptable performance in the absence of these histological procedures, although the best signal-to-noise ratio is found after 5-day primary antibody incubation and pre-treatments with $\mathrm{NaBH}_{4}$ and standard intensity HA-AR. (c) Staining with anti-DCX, anti-PSA-NCAM and anti-NeuN antibodies (5-day primary antibody incubation) after sample incubation with a $5 \% \mathrm{NaBH}_{4}$ solution and high-intensity HC-AR. Under these conditions, few $\mathrm{DCX}^{+}$cells can be identified (magenta triangles). It should be observed that the selective cytoplasmic signal of this marker disappears, and some staining is also observed in the nucleus. Moreover, blood vessels (green triangles) and autofluorescent or undefined structures (yellow triangles) are erroneously marked as $\mathrm{DCX}^{+}$. NeuN shows acceptable performance, although a higher background is observed under these experimental conditions. An increase in background intensity is observed for PSA-NCAM. (d) Staining with anti-DCX, anti-PSA-NCAM and anti-NeuN antibodies (after a short primary antibody incubation (24 h)) after sample incubation with a $0.5 \% \mathrm{NaBH}_{4}$ solution and standard-intensity HC-AR. DCX staining is sensitive to this shorter primary antibody incubation. Thus, the signal-to-noise ratio is significantly reduced. Some $\mathrm{DCX}^{+}$cells can be identified (magenta triangles), although neuritic processes are not intensely stained. A similar situation is observed in the case of the PSA-NCAM antibody. In contrast, the NeuN antibody shows good performance after $24 \mathrm{~h}$ of primary antibody incubation, although the best signal-to-noise ratio is found after a 5-day primary antibody incubation and pre-treatment with $\mathrm{NaBH}_{4}$ and standard-intensity HC-AR. Although the signal intensity is lower, $\mathrm{NeuN}^{+}$cells can be unambiguously identified in these preparations. Thus, as shown, the sensitivity of the antibodies to variations in the histological procedures differs markedly. (e) Quantification of the background fluorescence intensity in the different experimental conditions. To this end, the mean fluorescence intensity of 10 circular regions of interest (ROIs) of $161.5 \mu \mathrm{m}^{2}$ have been measured per image using ImageJ. Each image was obtained from a different brain section. Five to six brain sections obtained from the same subject have been analyzed per experimental condition. Individual dots indicate the average values obtained in each section. As shown, incubation with $0.5 \% \mathrm{NaBH}_{4}$ significantly reduced background intensity. On the other hand, $\mathrm{HC}$-AR alone does not cause any effect on this parameter. Combined $5 \% \mathrm{NaBH}_{4}$ treatment and high-intensity $\mathrm{HC}$-AR increase autofluorescence. (f) Histogram showing fluorescence intensity distribution in the different experimental conditions. Five to six images obtained from the same subject have been analyzed per experimental condition. White scale bar: $50 \mu \mathrm{m}$. Magenta triangles: $\mathrm{DCX}^{+}$cells. Yellow triangles: autofluorescent or undefined structures. Green triangles: blood vessels. Graphs represent means \pm SEM. $n=5-6$ sections obtained from the same subject analyzed per experimental condition. ${ }^{\star} 0.05>P \geq 0.01 ;{ }^{\star} 0.01>P \geq 0.001$. Asterisks indicate significance in a least significant difference (LSD) post-hoc test in a one-way ANOVA comparison. Raw data for panels (e) and (f) are in Supplementary Data 1. Brain tissue donation, processing and use for research were in compliance with published protocols ${ }^{38}$, which include the obtaining of informed consent for brain tissue donation from living donors and the approval of the whole donation process by the Ethical Committee of the Banco de Tejidos CIEN (Committee Approval Reference \#15-20130110\#).

the collection of new brain samples in advance of any proposed study. In this regard, the expertise of pathologists performing autopsies is determinant to guarantee homogeneity in the brain area sampled, accurateness of the dissection protocol and comparable duration of autopsy for all the subjects. Moreover, all experiments involving the use of samples of human origin must be performed following institutional, national and international guidelines. Thus, a variable amount of time may be required to secure approval of the pertinent ethics and biosecurity committees. This time should be factored in when planning experiments.

Moreover, to validate the staining of an antibody, previous experience of the research team, which should ideally combine neuropathologists, histologists and cellular biologists, is required to define the criteria for considering a given signal truly specific. These criteria should be validated for each new marker intended to be used. Given the poor functioning of numerous antibodies on human tissue, validation steps may therefore require the purchase of several antibodies to detect a single protein and thus bring about additional costs that cannot easily be calculated a priori. However, validation steps are of crucial importance given that differences in the procedures used might generate completely opposing results and data interpretation. In this regard, previous expertise of the team in immunohistochemical studies on human tissue is strongly recommended, as this will be extremely helpful in identifying potential confounding autofluorescent structures. Ideally, the antibody signal should be validated using synthetic blocking peptides that eliminate the binding sites of the antibody and permit comparison between the specific and unspecific signal of these molecules ${ }^{9}$. The steps of this protocol that require validation/optimization procedures have been indicated throughout the manuscript.

Consideration should also be given to the fact that fixation, histological manipulation and mounting might cause tissue shrinkage. Since this may affect cell density calculations, special effort 


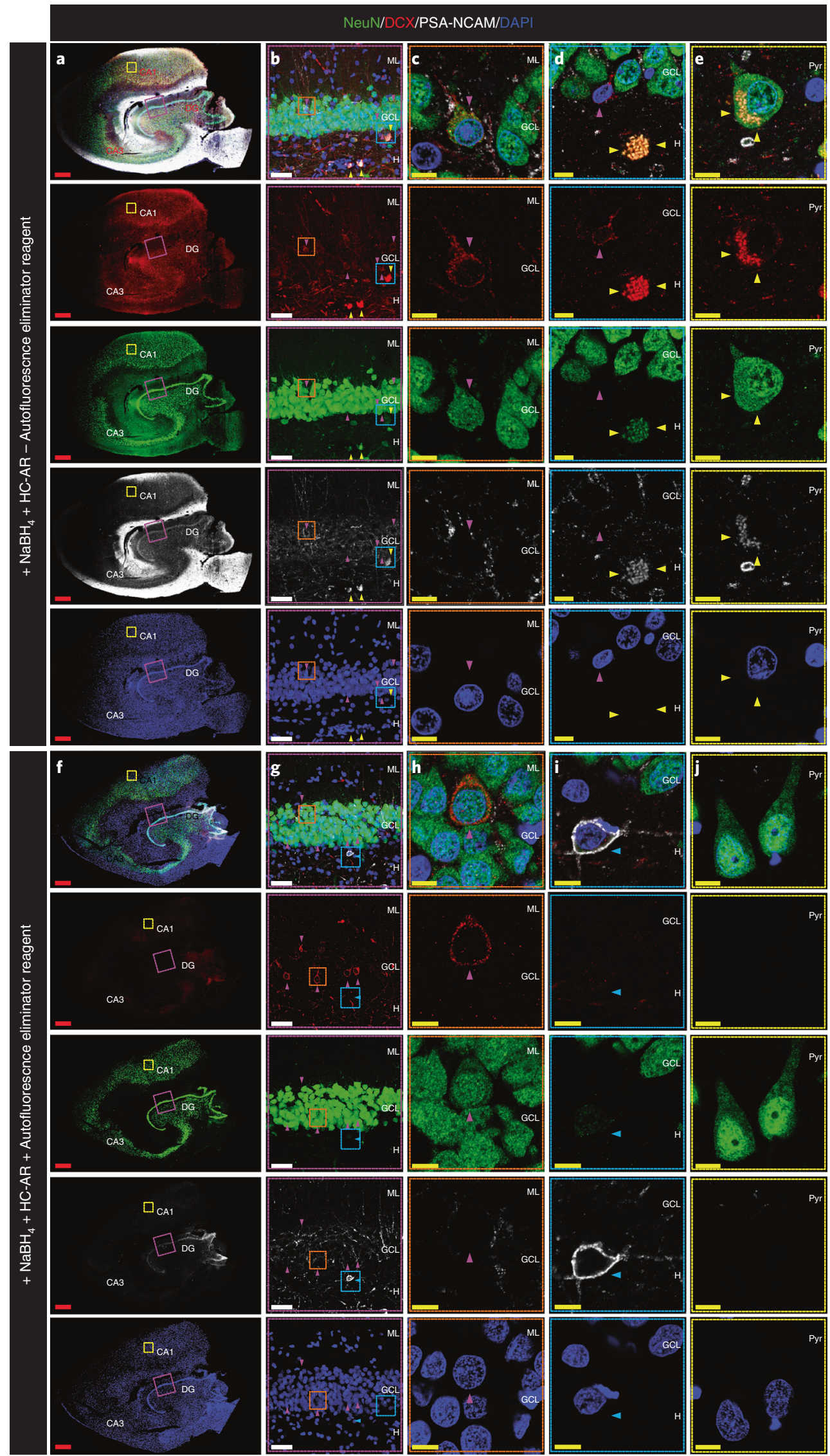


4 Fig. 5 I Effects of incubation with the autofluorescence eliminator reagent on the outcomes of the IHC. (a-e) Representative images of a tile-scan acquisition (a), 25x magnification (b), and high-power magnification images of the DG (c and $\mathbf{d}$ ) and the CA1 (e) hippocampal subfields in the absence of incubation with the autofluorescence eliminator reagent. DCX and PSA-NCAM staining show low intensity due to higher background. Moreover, autofluorescent structures, possibly lipofuscin aggregates (yellow triangles), can be observed both in the DG (d) and the CA1 (e) region. Note that autofluorescent structures appear as aggregated bodies in certain regions of the cell and can be observed in all the channels. (f-j) Representative images of a tile-scan acquisition (f), $25 \times$ magnification $(\mathbf{g})$, and high-power magnification images of the DG (h and $\mathbf{i})$ and the CA1 (j) hippocampal subfields after incubation with the autofluorescence eliminator reagent. Note the increase in the intensity of the DCX and PSA-NCAM signal and image cleanness, together with a reduction in the background $(\mathbf{f}-\mathbf{j})$. The presence of autofluorescent structures is no longer observable in the DG ( $\mathbf{g}-\mathbf{i})$ or the CA1 (j) regions. Pyr, pyramidal layer. Red scale bar: $200 \mu \mathrm{m}$. White scale bar: $50 \mu \mathrm{m}$. Yellow scale bar: $10 \mu \mathrm{m}$. Magenta triangles: $\mathrm{DCX}^{+}$cells. Yellow triangles: Autofluorescent structures. Light blue triangles: PSA-NCAM ${ }^{+}$cells. Brain tissue donation, processing and use for research were in compliance with published protocols ${ }^{38}$, which include the obtaining of informed consent for brain tissue donation from living donors and the approval of the whole donation process by the Ethical Committee of the Banco de Tejidos CIEN (Committee Approval Reference \#15-20130110\#).

should be made to guarantee the maximal homogeneity in the application of histological procedures to all the samples intended to be compared.

General limitations affecting all studies involving the use of post-mortem human samples include the inter-individual variability of lifestyle, habits, diet, education and comorbidity of other diseases associated with the cause of death, among others. These limitations are not easily addressed and are not derived per se from the protocol described here ${ }^{22}$. This protocol is intended to optimize the use of post-mortem human brain samples generously given by brain donors and their families, and to support further research into human AHN. Researchers are recommended to use large cohorts of individuals to minimize the putative bias caused by the aforementioned factors, among others. Moreover, careful reporting of as many epidemiological factors as are known will substantially help to improve comparison between data obtained from different laboratories ${ }^{22}$.

Finally, when post-mortem samples are used, control experiments should be performed to address the putative effect of the post-mortem delay (PMD) on the degradation/alteration rate of each protein studied $^{9,23}$. In this regard, in our initial study ${ }^{9}$, we showed that PMD intervals shorter than $38 \mathrm{~h}$ are suitable for the detection of several markers of AHN in the human DG, although a deleterious effect of PMDs longer than $38 \mathrm{~h}$ has been reported in rodents ${ }^{23}$. In this regard, researchers should perform time-course control experiments ${ }^{9}$ to determine whether the PMD or fixation time of a given collection of samples is suitable for the particular studies to be performed. If the samples available do not meet these criteria, or histological procedures cannot be further refined to obtain a signal of acceptable quality, searching for an alternative source of samples is strongly recommended.

\section{Experimental design}

A general scheme of the overall experimental design is given in Fig. 1. Fig. 2 shows a graphical overview of particularly sensitive steps of the protocol.

\section{Obtaining human samples (Steps 1-4)}

We use post-mortem samples of human origin obtained from autopsies of brain donor subjects ${ }^{9}$. We strongly recommend monitoring age, gender and PMD (namely the time elapsed between exitus (the exact time of death) and examining medical records) to address the cognitive status of each individual. Autopsies should be performed by a specialized neuropathologist in adequate facilities. Samples should be obtained under tightly controlled conditions, strictly controlling the type of fixative used and fixation time. In addition to careful examination of medical records, a detailed neuropathological study should be performed by a specialist to collect data such as Braak-Tau, Consortium to Establish a Registry for Alzheimer's Disease (CERAD) score for neuritic plaques, and Braak- $\alpha$-synuclein (which are commonly used to determine pathological status in Alzheimer's and Parkinson diseases, respectively ${ }^{24}$ ), among others. During the autopsy, and after removal of the brain from the skull (Fig. 2a), the hemispheres must be separated (Fig. 2b) and the meninges carefully removed (Fig. 2c). Next, the area of interest should be dissected (Fig. 1a). To this end, the use of external anatomic references to dissect the area of interest is recommended. This is of particular importance to ensure homogeneity in the sampled area for all the individuals. To study the posterior portion of the anterior hippocampus, we identified both the posterior pole of the mammillary bodies and that of the uncus to dissect the hippocampal area of interest in our original manuscript ${ }^{9}$. 


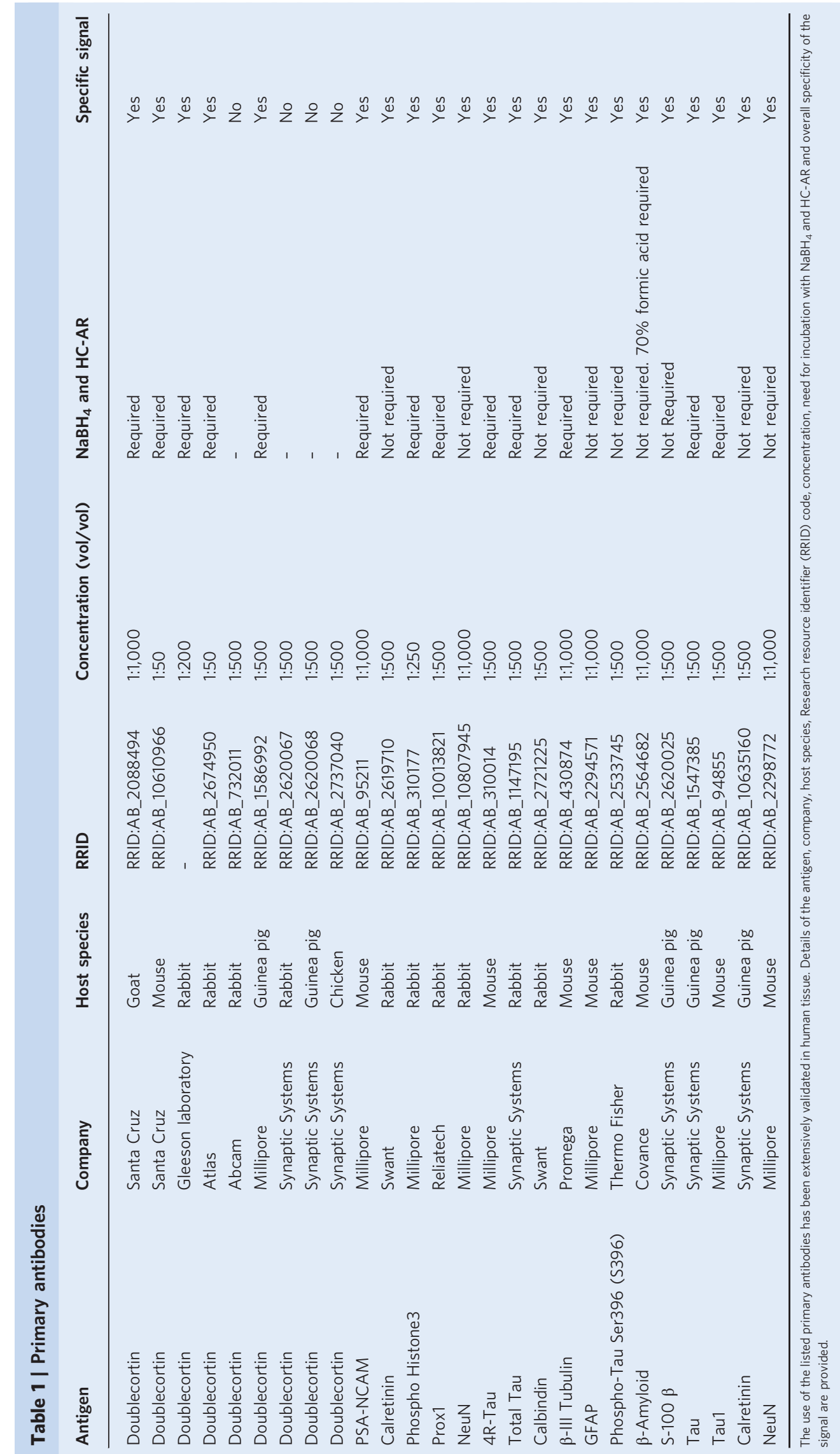


Table 2 | Secondary antibodies

\begin{tabular}{llllll} 
Antibody & Company & Host species & Catalog number & RRID & Concentration (vol/vol) \\
\hline Alexa-488 anti-chicken & Thermo Fisher Scientific & Goat & A-11039 & RRID:AB_2534096 & $1: 1,000$ \\
Alexa-488 anti-mouse & Thermo Fisher Scientific & Donkey & A-21202 & RRID:AB_141607 & $1: 1,000$ \\
Alexa-488 anti-rabbit & Thermo Fisher Scientific & Donkey & A-21206 & RRID:AB_2535792 & $1: 1,000$ \\
Alexa-488 anti-rat & Thermo Fisher Scientific & Donkey & A-21208 & RRID:AB_2535794 & $1: 1,000$ \\
Alexa-555 anti-chicken & Thermo Fisher Scientific & Goat & A-21437 & RRID:AB_2535858 & $1: 1,000$ \\
Alexa-555 anti-goat & Thermo Fisher Scientific & Donkey & A-21432 & RRID:AB_2535853 & $1: 1,000$ \\
Alexa-555 anti-guinea pig & Thermo Fisher Scientific & Goat & A-21435 & RRID:AB_2535856 & $1: 1,000$ \\
Alexa-555 anti-mouse & Thermo Fisher Scientific & Donkey & A-31570 & RRID:AB_2536180 & $1: 1,000$ \\
Alexa-555 anti-rabbit & Thermo Fisher Scientific & Donkey & A-31572 & RRID:AB_162543 & $1: 1,000$ \\
Alexa-555 anti-rat & Thermo Fisher Scientific & Goat & A-21434 & RRID:AB_141733 & $1: 1,000$ \\
Alexa-647 anti-chicken & Thermo Fisher Scientific & Goat & A-21449 & RRID:AB_2535866 & $1: 1,000$ \\
Alexa-647 anti-goat & Thermo Fisher Scientific & Donkey & A-21447 & RRID:AB_2535864 & $1: 1,000$ \\
Alexa-647 anti-guinea pig & Thermo Fisher Scientific & Goat & A-21450 & RRID:AB_2735091 & $1: 1,000$ \\
Alexa-647 anti-mouse & Thermo Fisher Scientific & Donkey & A-31571 & RRID:AB_162542 & $1: 1,000$ \\
Alexa-647 anti-rabbit & Thermo Fisher Scientific & Donkey & A-31573 & RRID:AB_2536183 & $1: 1,000$ \\
Alexa-647 anti-rat & Thermo Fisher Scientific & Goat & A-21247 & RRID:AB_141778 & $1: 1,000$ \\
Pacific blue anti-mouse & Thermo Fisher Scientific & Goat & P-31582 & RRID:AB_10374586 & $1: 1,000$
\end{tabular}

The use of the listed secondary antibodies has been extensively validated in human tissue. The name, company, host species, catalog number, RRID code and concentration are provided. All these antibodies have rendered a specific and validated signal.

Once this area has been dissected, small blocks of tissue should be obtained (Fig. 2d). The dimensions of these blocks must be determined in relation to the sectioning method that is going to be used. For instance, when using a sliding blade vibratome, block size is limited by the width of the blade $(\sim 4 \mathrm{~cm})$. Importantly, fresh brain tissue requires extremely careful manipulation, to obtain blocks with flat surfaces, which might help prevent tissue damage during sectioning.

\section{Tissue processing (Steps 5-17)}

Tissue processing determines the outcomes of IHC on samples of human origin ${ }^{9,25}$ (Fig. 3). Thus, slight variations in these steps prevent the detection of several markers of AHN in human tissue ${ }^{9}$, such as the gold-standard marker for immature neurons, namely the microtubule-associated protein doublecortin $(\mathrm{DCX})^{26,27}$. Graphic examples of how variations in these steps affect the outcome of IHC are provided in Figs. 3-5, to serve as a reference for the fine-tuning of the IHC protocol to the researcher's requirements. After obtaining tissue blocks, they should be rapidly placed in a falcon tube filled with fixative ( $4 \%$ freshly prepared paraformaldehyde (PFA) solution is strongly recommended) and fixed at $4{ }^{\circ} \mathrm{C}$ for $24 \mathrm{~h}$ (Fig. 1a). Note that the fixation time should be adjusted slightly depending on tissue block thickness since the fixative must completely penetrate the tissue ${ }^{25}$. As a reference, PFA penetrates the tissue at a rate of $1 \mathrm{~mm} / \mathrm{h}^{25}$. We have previously determined that a 24 -h fixation in freshly prepared $4 \%$ PFA is suitable for up to $9-\mathrm{mm}^{3}$ human brain tissue blocks and the detection of most antigens by IHC (Tables 1 and 2). Note that tissue robustness (namely its resistance to damage during sectioning) increases with fixation time. However, fixation times exceeding $12 \mathrm{~h}$ usually require tissue pre-treatment (see next section) to allow the detection of certain antigens ${ }^{9,15}$ (Fig. 4). Previously validated primary antibodies and pre-treatment steps are summarized in Table 1 . In this regard, it is widely accepted that prolonged fixation time with aldehydes markedly dampens, or even prevents, the detection of numerous cell markers in the human brain ${ }^{25,28}$. This point is particularly relevant for markers of $\mathrm{AHN}^{9}$. We have previously shown that, depending on the fixative, fixation time, tissue pre-processing methodology and antibody used, totally opposing results can be obtained ${ }^{9}$ (Figs. 3-5). We strongly recommend that exhaustive time-course control fixation experiments be performed for each antibody of interest ${ }^{9}$.

After completion of fixation, tissue blocks should be washed three times in $0.1 \mathrm{~N}$ phosphate buffer $(\mathrm{PB})$ to completely remove traces of fixative before tissue sectioning. We usually immerse tissue blocks in a $10 \%$ sucrose- $4 \%$ agarose solution diluted in $0.2 \mathrm{~N} \mathrm{~PB}$ to increase their robustness during sectioning with a sliding blade vibratome (Figs. $1 \mathrm{~b}$ and $2 \mathrm{e}-\mathrm{h}$ ). Sectioning parameters (e.g., blade speed and amplitude) should be adjusted according to tissue robustness (Figs. $1 \mathrm{~b}$ and $2 \mathrm{~h}-\mathrm{j}$ ). 
Next, $50-\mu \mathrm{m}$-thick sections should be collected in multi-well plates filled with $0.1 \mathrm{~N} \mathrm{~PB}$ using a soft brush (Figs. $1 \mathrm{~b}$ and $2 \mathrm{i}-\mathrm{j}$ ). After completion of this step, sections should be transferred to a new 96-well plate filled with glycerol-based cryopreservative solution and immediately placed at $-20{ }^{\circ} \mathrm{C}$. One section should be placed inside each well. Sections immersed in this solution can be stored in the freezer until needed ${ }^{9}$.

\section{IHC and brain section pre-treatment (Steps 18-36)}

In addition to tissue processing, both section pre-treatment and IHC methodology critically influence the detection of numerous markers of AHN in human tissue 9 (Figs. 4 and 5). Our protocol includes subjecting brain sections to two key steps before IHC (Fig. 1c), namely incubation with $\mathrm{NaBH}_{4}$ (Fig. 2k) and heat-mediated citrate buffer antigen retrieval (HC-AR) at $80{ }^{\circ} \mathrm{C}$ (Fig. 2l-p). Incubation with $\mathrm{NaBH}_{4}$ is used to remove the autofluorescence caused by aldehyde fixation ${ }^{29}$. It should be noted that incubation with $\mathrm{NaBH}_{4}$ results in a reduction in the background fluorescence intensity (Fig. 4e). Moreover, HC-AR is necessary for some antigens to be recognized by antibodies, although it does not change the overall fluorescence intensity of the background. We strongly recommend that the intensity of these pre-treatment steps be adjusted to the specific requirements of the study before the actual experiment is started. In this regard, incubation with a higher concentration of $\mathrm{NaBH}_{4}$ and the application of a high-intensity HC-AR may result in an increased background (Fig. 4e,f) and loss of antibody-specific signal ${ }^{9}$. Table 1 indicates the need for these steps for several previously validated antibodies. The effects of these treatments on IHC outcome are exemplified in Fig. 4.

Next, IHC should be performed in a buffer that contains $0.1 \mathrm{~N} \mathrm{~PB}$ and in the presence of a blocking agent (1\% BSA) and a detergent (1\% Triton X-100). BSA is used to prevent unspecific binding of antibodies to brain tissue, and thus, to reduce background. On the other hand, Triton $\mathrm{X}-100$ permeabilizes the tissue and allows antibody binding to antigens. As previously mentioned, antibodies should be carefully selected and validated, ideally on human samples, in advance. As a general recommendation, the use of several antibodies detecting the same protein, together with pilot antibody pre-adsorption experiments in which synthetic blocking peptides are used, can ensure the specificity of the signal obtained. Using this methodology, we have previously validated the signal obtained with various anti-DCX antibodies that recognize this gold-standard marker for immature neurons $^{27}$ (Fig. 3). Moreover, we recommend comparison of a range of antibody incubation times, given that not all markers are equally sensitive to variations in the same (Fig. 4). An additional difficulty commonly encountered when analyzing human tissue by IHC is the presence of autofluorescent structures $^{16,30}$ (Fig. 5). Fig. 5d,e shows examples of these structures, which may erroneously be considered positive signals. In fact, an aggregated-scattered condensation with a "c-shape" in the cytoplasm (Fig. 5e) usually indicates the presence of lipofuscin aggregates ${ }^{31,32}$. In this regard, after performing IHC, we always incubate brain sections with an autofluorescence eliminator reagent ${ }^{9}$ (Fig. 1c). As shown in Fig. 5, the use of this reagent considerably reduces the autofluorescence of these structures. We strongly recommend the application of morphometric criteria to identify truly selective signals when working on tissues of human origin. These criteria should be previously defined for each of the cell markers analyzed. Examples of these criteria are provided in Image analysis and Fig. 5d,e. For instance, confirmation of regular staining throughout the whole structure that theoretically should be labeled and the exclusion of scattered patterns observable in several channels (Fig. 5d,e) are recommended criteria. In addition, the presence of all of the positive structures in DAPI-positive cells should be verified. In addition, the nuclear morphology of these cells should correlate with that of the cell type in which staining is expected or has been previously reported. Moreover, rigorous controls in the absence of primary and secondary antibodies should always be performed. A final consideration regards the expected cellular distribution for a given marker. For instance, in those cases in which the used antibody is theoretically detecting a microtubule-associated protein, such as DCX, cytoplasmic and neuritic staining is expected. Therefore, if nuclear staining is observed, it should not be considered a positive cell. Instead, a clear cytoplasmic pattern of staining, comparable to that described in other mammalian species, should be pursued ${ }^{26}$. Note that certain parameters, such as increased fixation times, can cause an apparent shift in staining pattern for several markers of AHN in human tissue ${ }^{9}$ (Fig. 3).

Image acquisition and analysis (Steps 37-44)

After completion of IHC, confocal image acquisition should be performed immediately, avoiding the elapse of variable periods of time between subjects or determinations. Given the high background present in human samples in comparison with murine tissues, we recommend that images be 
Fig. 6 I Image analysis. An overview of the stereological methods used to analyze confocal images is summarized. (a) Determination of the reference volume for $\mathrm{DCX}^{+}$cell counts. Briefly, the area of the GCL is determined on max $z$-projection images. This area is multiplied by the $z$-thickness of the stack to calculate the reference volume inside which cells will be counted. (b) Determination of the reference volume for $\mathrm{NeuN}^{+} \mathrm{DGC}$ counts. Briefly, the $X$ and $Y$ dimensions of the images are multiplied by the z-thickness of the stack to obtain the reference volume inside which the cells are counted. (c) Physical dissector method modified for confocal microscopy and applied for DCX ${ }^{+}$cell counts $9,33,37$. Each cell is represented with a number in the plane in which it appears for the first time. Subsequently, an " $x$ " is placed on the same location of other planes to avoid a single cell being counted multiple times. (d) Physical dissector method modified for confocal microscopy and applied for NeuN ${ }^{+}$DGC counts $9,33,37$. Each cell is represented with a number in the plane in which it appears for the first time. Subsequently, an " $x$ " is placed on the same location of other planes to avoid a single cell being counted multiple times. (e) Formula used to calculate cell densities from total number of cells and the reference volume. (f) Colocalization analyses. Briefly, a cell of interest is localized, and the expression of other cell markers is verified. A triple-labeled, namely DCX ${ }^{+}, \mathrm{NeuN}^{+} \mathrm{PSA}^{-N_{C A M}}{ }^{+}$, cell is indicated by a magenta triangle. In contrast, a single-labeled $\mathrm{DCX}^{+}$cell is indicated with a white triangle. (g) Identification of the hilar and molecular borders of the GCL (discontinuous white lines). This structure can be divided into regions (discontinuous yellow lines), and the number of cells inside each subregion can be counted. (h) Measurement of cell position within the GCL. The distance between the hilar border and each cell can be measured by tracing a perpendicular line. (i) Measurement of the number and position of neurites. The number and orientation of each individual neurite can be analyzed for each cell. Neurites are indicated with triangles. (j) Analysis of cell marker expression. Once the cell population of interest has been identified, the expression of distinct cell markers can be determined by measuring fluorescence intensity. To this end, the cell contour is drawn manually. Next, fluorescence intensity for any of the additional markers is measured in Fiji. An example of the quantification of NeuN expression in $\mathrm{DCX}^{+}$(red) and $\mathrm{DCX}^{-}$(yellow) cells is shown. It can be observed how NeuN expression is lower in the former, possibly indicating that these cells have recently started to express NeuN. The NeuN fluorescence intensity of both $\mathrm{NeuN}^{+} \mathrm{DCX}^{-}$and $\mathrm{NeuN}^{+} \mathrm{DCX}^{+}$cells is measured in the same plane, to provide a control for fluorescence variation between planes. (k) Determination of cell soma area. To determine this parameter, the soma contour is drawn. Next, the area is measured using Fiji software. The area of $\mathrm{DCX}^{+} /$calbindin $(\mathrm{CB})^{+}$(yellow) and $\mathrm{DCX}^{-} / \mathrm{CB}^{+}$ (pink) cells is shown. As can be observed, this area is smaller in $\mathrm{DCX}^{+}$than in $\mathrm{DCX}^{-}$cells, possibly indicating the more immature state of these cells. White scale bar: $50 \mu \mathrm{m}$. Yellow scale bar: $10 \mu \mathrm{m}$. Magenta scale bar: $5 \mu \mathrm{m}$. In (f),

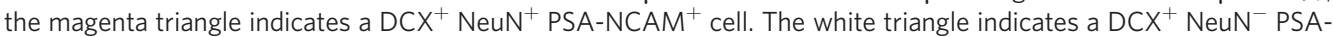
$\mathrm{NCAM}^{-}$cell. In (g), white lines indicate the hilar and molecular borders of the GCL. Yellow lines indicate the subdivision of this structure into regions. In (h), arrows indicate the measurement of cell position within the GCL. In (i), triangles indicate the presence of neurites. Graphs represent means \pm SEM. $n=13$ neurologically healthy control subjects. ${ }^{\star} 0.05>P \geq 0.01 ;{ }^{\star \star \star} 0.01>P \geq 0.001$. Brain tissue donation, processing and use for research were in compliance with published protocols ${ }^{38}$, which include the obtaining of informed consent for brain tissue donation from living donors and the approval of the whole donation process by the Ethical Committee of the Banco de Tejidos CIEN (Committee Approval Reference \#15-20130110\#).

acquired under a confocal microscope rather than an epifluorescence microscope (Fig. 1d). Direct visualization under fluorescent light should be limited to the shortest time possible, to avoid fluorophore quenching. Depending on the cell marker analyzed, a variable number of images should be acquired per subject. In this regard, high variability in the relative abundance of distinct cell markers is observed in individuals of different ages or affected by different diseases ${ }^{9,12}$. We therefore strongly recommend a pilot acquisition experiment to calculate intra- and inter-subject variability ${ }^{33}$ for each cell marker of interest. Moreover, to avoid potential bias during sampling and cell counting, stereological methods ${ }^{34-36}$ should be used both to acquire images and to perform cell counts s, $^{93,37}$ (Fig. 6). We used a modified physical fractionator method for confocal microscopy ${ }^{33}$. Briefly, this method consists of acquiring stacks of images under a confocal microscope, followed by the determination of the reference volume inside which these cells are counted and the quantification of cell densities inside the reference volume ${ }^{9,33}$ (Fig. 6a-e). We suggest that manuscripts should clearly state the structure that has been selected as the reference volume. For instance, when cells expressing markers of AHN are being counted, considering only the granule cell layer (GCL) as the reference volume may render cell densities orders of magnitude higher than those that would have been obtained if the whole DG or the hippocampus were considered ${ }^{9,12}$.

\section{Materials}

\section{Biological materials}

- Human samples ! CAUTION All experiments involving the use of human samples must be performed in accordance with the relevant institutional and national regulations. The use of post-mortem brain tissue samples in our studies was coordinated by the local Brain Bank (Banco de Tejidos CIEN, Madrid, Spain), following Spanish laws and international ethical and technical guidelines on the use of human samples for biomedical research purposes ${ }^{38}$. In all cases, brain tissue donation, processing and 
a

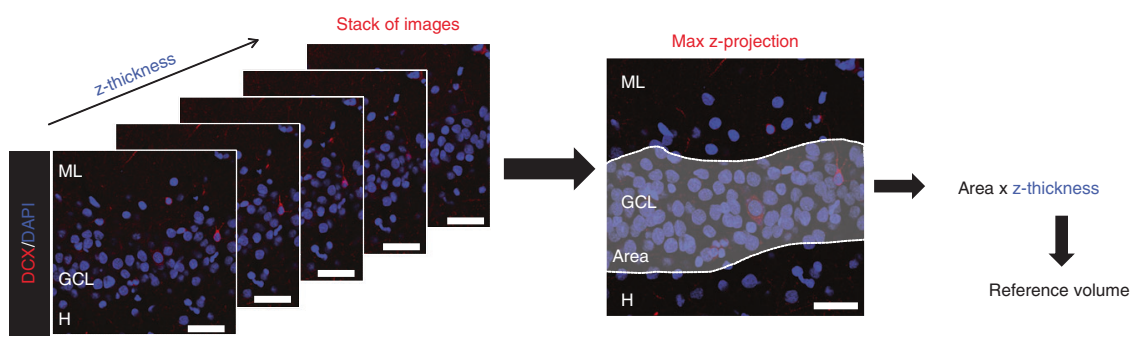

b

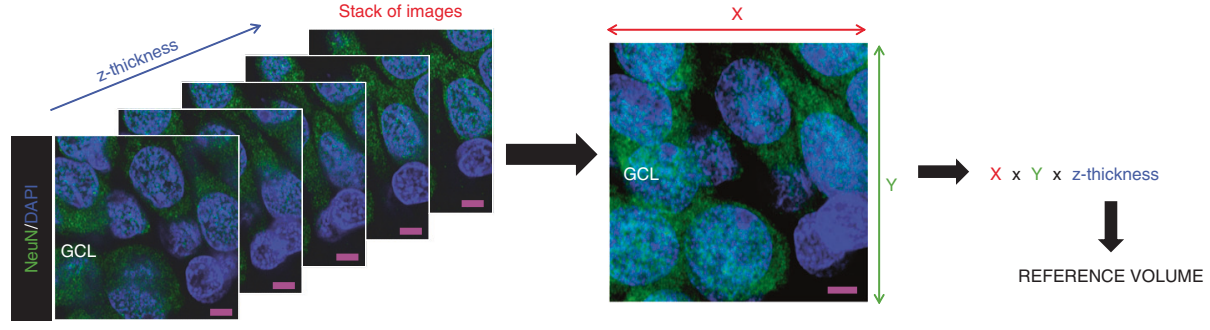

c

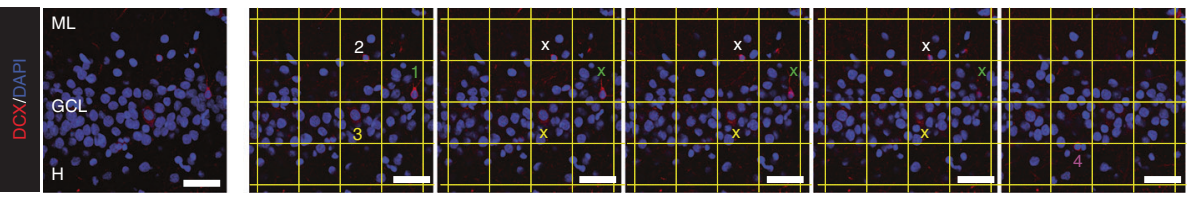

d
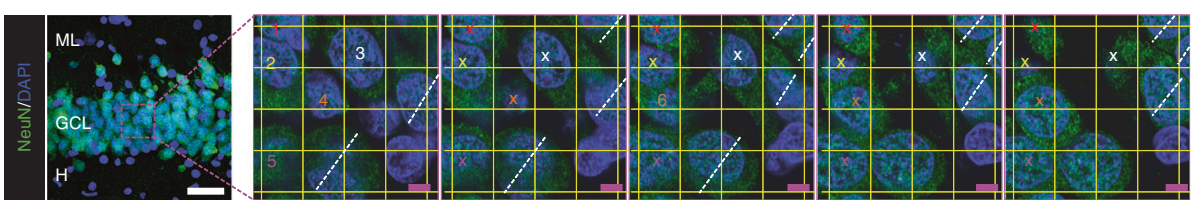

e

Cell density (number of cells $/ \mathrm{mm}^{3}$ )

Number of cells inside the reference volume

Reference volume $\left(\mathrm{mm}^{3}\right)$
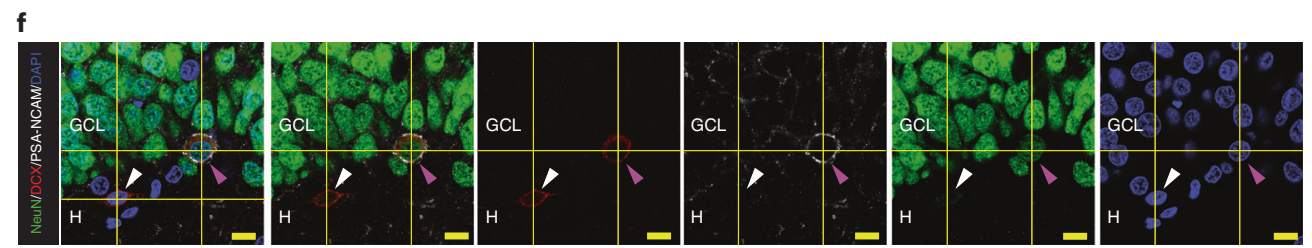

g

h
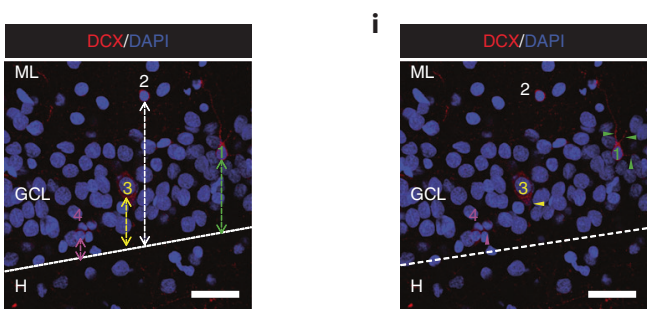

j
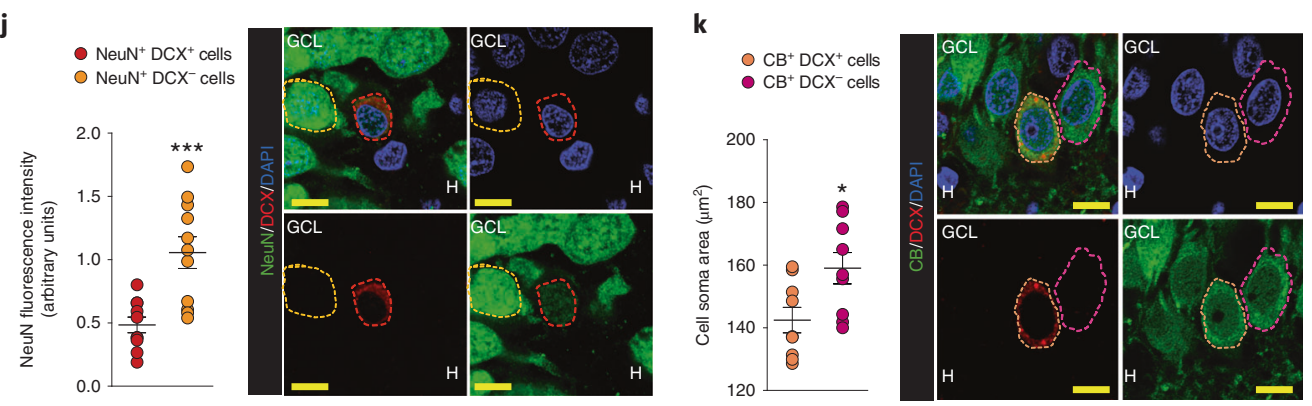
Table 3 | Epidemiological data of the subjects who participated in this study

\begin{tabular}{|c|c|c|c|c|c|c|c|c|}
\hline Subject & Age & Gender & PMD (H) & Cause of death & CERAD & Braak-Tau & Braak- $\alpha$-synuclein & Fixative \\
\hline Control 1 & 52 & Female & 6 & Cancer & 0 & 0 & 0 & $4 \%$ PFA, $24 \mathrm{~h}$ at $4{ }^{\circ} \mathrm{C}$ \\
\hline Control 2 & 43 & Male & 5 & Leukemia & 0 & 0 & 0 & $\begin{array}{l}4 \% \text { PFA, } 6 \text { or } 24 \text { h at } 4{ }^{\circ} \mathrm{C} \text {, } \\
\text { or } 3.7 \% \text { formalin, } 6 \text { months }\end{array}$ \\
\hline Control 3 & 68 & Male & 4 & Multisystemic atrophy & 0 & 0 & 0 & $4 \%$ PFA, $24 \mathrm{~h}$ at $4{ }^{\circ} \mathrm{C}$ \\
\hline Control 4 & 78 & Male & 3 & Aortic dissection & 0 & 0 & 0 & $4 \%$ PFA, $24 \mathrm{~h}$ at $4{ }^{\circ} \mathrm{C}$ \\
\hline Control 5 & 75 & Female & 5 & Cancer & 0 & 0 & 0 & $4 \%$ PFA, $24 \mathrm{~h}$ at $4{ }^{\circ} \mathrm{C}$ \\
\hline Control 6 & 85 & Male & 23 & Peritonitis & 0 & 0 & 0 & $4 \%$ PFA, $24 \mathrm{~h}$ at $4{ }^{\circ} \mathrm{C}$ \\
\hline Control 7 & 64 & Male & 7 & Aortic dissection & 0 & 0 & 0 & $4 \%$ PFA, $24 \mathrm{~h}$ at $4{ }^{\circ} \mathrm{C}$ \\
\hline Control 8 & 83 & Female & 4 & Stroke & 0 & 0 & 0 & $4 \%$ PFA, $24 \mathrm{~h}$ at $4^{\circ} \mathrm{C}$ \\
\hline Control 9 & 61 & Male & 8 & Hemorragia & 0 & 0 & 0 & $4 \%$ PFA, $24 \mathrm{~h}$ at $4{ }^{\circ} \mathrm{C}$ \\
\hline Control 10 & 61 & Female & 8 & Cancer & 0 & 0 & 0 & $4 \%$ PFA, $24 \mathrm{~h}$ at $4{ }^{\circ} \mathrm{C}$ \\
\hline Control 11 & 65 & Male & 18 & Stroke & 0 & 0 & 0 & $4 \%$ PFA, $24 \mathrm{~h}$ at $4^{\circ} \mathrm{C}$ \\
\hline Control 12 & 63 & Male & 38 & Stroke & 0 & 0 & 0 & $4 \%$ PFA, $24 \mathrm{~h}$ at $4^{\circ} \mathrm{C}$ \\
\hline Control 13 & 87 & Male & 6.5 & Sepsis & 0 & 0 & 0 & $4 \%$ PFA, $24 \mathrm{~h}$ at $4^{\circ} \mathrm{C}$ \\
\hline
\end{tabular}

Age, gender, PMD, cause of death, CERAD stage, Braak-Tau stage, Braak- $\alpha$-synuclein stage, type of fixative used and fixation time.

use for research were in compliance with published protocols ${ }^{38}$, which include the obtaining of informed consent for brain tissue donation from living donors and the approval of the whole donation process by the Ethical Committee of the Banco de Tejidos CIEN (Committee Approval Reference \#1520130110\#).

- Epidemiological data about human samples. Table 3 provides the epidemiological data of the subjects whose measurements are shown in Fig. 6. All the images shown in this manuscript correspond to postmortem human samples obtained from a neurologically healthy control subject (Control 2). The epidemiological data of this subject are the following: gender, male; age, 43; PMD, $5 \mathrm{~h}$; cause of death, leukemia; Braak-Tau stage, 0; CERAD stage, 0; and Braak $\alpha$-synuclein stage, 0 A CRITICAL As much epidemiological information as possible is desirable relating to the following criteria: age, gender, PMD, cause of death and neuropathological information (such as Brak-Tau and CERAD stages).

- Information about the type of fixative used and the fixation time for each sample

\section{Reagents}

Tissue dissection, fixation, inclusion, sectioning and preservation

- PFA electron microscopy (EM) Grade (16\% wt/vol) (Electron Microscopy Sciences, catalog number 15710) ! CAUTION PFA is toxic, mutagenic and carcinogenic and an irritant. Perform all procedures in a fume hood while wearing gloves, a mask and goggles.

- $\mathrm{K}_{2} \mathrm{HPO}_{4}$ (Merck-Millipore, catalog number 105101)

- $\mathrm{NaH}_{2} \mathrm{PO}_{4}-\mathrm{H}_{2} \mathrm{O}$ (Merck-Millipore, catalog number 567545)

- Low-melting point agarose (Conda, catalog number 8010.00)

- Sucrose (Merck-Millipore, catalog number 107653)

- Cyanoacrylate glue (Sigma-Aldrich, catalog number Z105899-1EA) ! CAUTION Cyanoacrylate glue can cause skin irritation and is toxic. Manipulate carefully and wear protective gloves.

- Ethylene glycol (Sigma-Aldrich, catalog number 324558-2L) ! CAUTION Ethylene glycol is toxic and carcinogenic as well as an irritant. Perform all procedures in a fume hood while wearing gloves, a mask and goggles.

- Glycerol (85\%) (Honeywell Laboratories, catalog number 49783) ! CAUTION Glycerol is an irritant. Perform all procedures while wearing gloves, a mask and goggles.

IHC

- $\mathrm{K}_{2} \mathrm{HPO}_{4}$ (Merck-Millipore, catalog number 105101)

- $\mathrm{NaH}_{2} \mathrm{PO}_{4}-\mathrm{H}_{2} \mathrm{O}$ (Merck-Millipore, catalog number 567545)

- $\mathrm{NaBH}_{4}$ (Sigma-Aldrich, catalog number 213462-25G) !CAUTION NaBH 4 is toxic if swallowed. Perform all procedures in a fume hood while wearing gloves, a mask and goggles. 
- Citrate-based antigen retrieval solution (10X) (Vector \#3300)

- Triton X-100 (Sigma-Aldrich, catalog number 93443) ! CAUTION Triton X-100 is an irritant. Perform all procedures while wearing gloves, a mask and goggles.

- BSA (Sigma-Aldrich, catalog number A7888) ! CAUTION Perform all procedures while wearing gloves, a mask and goggles.

- Primary antibodies; examples of those we have used successfully are detailed in Table 1.

- Secondary antibodies; examples of those we have used successfully are detailed in Table 2.

- DAPI (Merck-Millipore, catalog number 268298) ! CAUTION Chemical dyes that have DNA-binding ability can be mutagenic or toxic. DAPI should be carefully handled like a potential mutagen. Always wear protective gloves.

- Ethanol (96\%) (Merck-Millipore, catalog number 159010) ! CAUTION Ethanol is an irritant. Perform all procedures while wearing gloves and goggles.

- Autofluorescence eliminator reagent (EMD Millipore, catalog number 2160) ! CAUTION Auto-uorescence eliminator reagent is toxic, carcinogenic and flammable and an irritant. Perform all procedures in a fume hood while wearing gloves, a mask and goggles.

- Mowiol 4-88 (Merck-Millipore, catalog number 475904)

- Glycerol (100\%) (Sigma-Aldrich, catalog number G9012)

- Trizma base (Sigma-Aldrich, catalog number T1503)

- $\mathrm{HCl}$ (Merck-Millipore, catalog number 113136) ! CAUTION $\mathrm{HCl}$ is toxic if swallowed. Perform all procedures in a fume hood while wearing gloves, a mask and goggles.

- Glycerol (85\%) (Honeywell Laboratories, catalog number 49783) ! CAUTION Glycerol is an irritant. Perform all procedures while wearing gloves, a mask and goggles.

- Gelatin from porcine skin (Sigma-Aldrich, catalog number G2625) ! CAUTION Perform all procedures while wearing gloves, a mask and goggles.

- $\mathrm{KCr}\left(\mathrm{SO}_{4}\right)_{2}$ (Merck-Millipore, catalog number 101036) ! CAUTION $\mathrm{KCr}\left(\mathrm{SO}_{4}\right)_{2}$ is an irritant. Perform all procedures while wearing gloves, a mask and goggles.

\section{Equipment}

\section{Lab supplies}

- Multi-well plastic plates (Corning, catalog number 3337)

- Scalpels (Swann-Morton, catalog number 2337)

- Blades (Electron Microscopy Sciences, catalog number 72003-01)

- Glass scintillation vials (Fisher Scientific, catalog number 03-337-7)

- Small paint brushes (Van Gogh, catalog number 191-00000-90919195)

- Microscopy glass slides (Thermo Scientific, catalog number 631-0411)

- $24 \times 60 \mathrm{~mm}$ microscopy glass coverslips (Thermo Scientific, catalog number 631-1575)

- Glass staining jars, racks and handles

\section{Standard lab equipment}

- Microwave

- Sliding-blade vibratome (Leica, catalog number VT-1200S)

- Freezer

- Water bath

- Magnetic shaker

- Orbital shaker

- Vortex

\section{Image acquisition and analysis}

- LSM800 Zeiss confocal microscope

- Computer with a multi-core processor and $\geq 4$ GB of RAM

\section{Software}

- Zen Blue 2.3 Windows 7 64-bits

- Fiji (ImageJ 1.52p Wayne Rasband, National Institutes of Health, USA, http://imagej.nih.gov/ij). Java 1.8.0_66 (64-bits) 


\section{Reagent setup}

0.2 N PB

To prepare 11 of this solution, add $28 \mathrm{~g}$ of $\mathrm{K}_{2} \mathrm{HPO}_{4}$ to $800 \mathrm{ml}$ of bidistilled water. After it has dissolved completely, add $5.3 \mathrm{~g}$ of $\mathrm{NaH}_{2} \mathrm{PO}_{4}-\mathrm{H}_{2} \mathrm{O}$. Adjust $\mathrm{pH}$ to 7.4 and the final volume to 11 with bidistilled water. This stock solution can be prepared and stored at room temperature ( $\mathrm{rt} ; 20-25^{\circ} \mathrm{C}$ ) for $\leq 6$ months.

4\% PFA fixative solution $(\mathrm{pH}=7.4)$

Dilute the commercial 16\% PFA solution in $0.2 \mathrm{~N} \mathrm{~PB}$ and distilled water (1:2:1 ( $\mathrm{vol} / \mathrm{vol} / \mathrm{vol})$ ). Prepare this solution freshly before autopsy. Adjust $\mathrm{pH}$ to 7.4 if necessary.

\section{$0.1 \mathrm{~N}$ PB}

Prepare this solution by diluting $0.2 \mathrm{~N}$ PB solution with bidistilled water $(1: 1(\mathrm{vol} / \mathrm{vol}))$. This solution can be prepared and stored at $\mathrm{rt}$ for $\leq 6$ months.

$10 \%$ sucrose- $4 \%$ agarose solution $(500 \mathrm{ml})$

Heat $500 \mathrm{ml}$ of $0.1 \mathrm{~N} \mathrm{~PB}$. Add $50 \mathrm{~g}$ of sucrose and shake vigorously on a magnetic shaker. After the sucrose has completely dissolved, add $20 \mathrm{~g}$ of agarose. Microwave the solution until bubbles start to form. Shake vigorously on a magnetic shaker for $30 \mathrm{~s}$ to $1 \mathrm{~min}$. Repeat a few microwave + shake cycles until a change in the consistency of the solution (increased viscosity and transparency) is observed. At this point, the solution is ready to use. This solution can be used immediately, aliquoted and stored at $-20{ }^{\circ} \mathrm{C}$ for $\leq 6$ months, or stored at $4{ }^{\circ} \mathrm{C}$ for $\leq 1$ week.

\section{Cryopreservative solution}

To prepare $1 \mathrm{l}$ of this solution, mix $300 \mathrm{ml}$ of polyethylene glycol with $100 \mathrm{ml}$ of $0.2 \mathrm{~N} \mathrm{~PB}, 300 \mathrm{ml}$ of $85 \%$ glycerol and $300 \mathrm{ml}$ of bidistilled water. This stock solution can be prepared in advance and stored at $\mathrm{rt}$ for $\leq 6$ months.

\section{$0.5 \% \mathrm{NaBH}_{4}$ solution}

Dissolve $5 \mathrm{mg}$ of $\mathrm{NaBH}_{4}$ in $1 \mathrm{ml}$ of $0.1 \mathrm{~N}$ PB. Final volume should be calculated taking into account that $1 \mathrm{ml}$ is needed per sample. $\mathrm{NaBH}_{4}$ solution should be prepared immediately before use.

\section{$1 \times$ citrate buffer $(\mathrm{pH} \mathrm{6.0)}$ antigen retrieval solution}

Dilute the commercial $10 \times$ citrate buffer $(\mathrm{pH}$ 6.0) antigen retrieval solution in bidistilled water (1:9 $(\mathrm{vol} / \mathrm{vol})$ ). Final volume should be calculated taking into account that $5 \mathrm{ml}$ is needed per sample (when using 10-ml scintillation vials). Citrate buffer ( $\mathrm{pH}$ 6.0) antigen retrieval solution should be prepared immediately before use.

\section{PB-Triton-BSA (PBT-BSA) solution}

To prepare $100 \mathrm{ml}$ of this solution, dissolve $1 \mathrm{~g}$ of BSA ( $1 \% \mathrm{wt} / \mathrm{vol})$ in $100 \mathrm{ml}$ of $0.1 \mathrm{~N} \mathrm{~PB}$. Add $1 \mathrm{ml}$ of Triton-X-100 (1\% vol/vol) and mix on a magnetic shaker until complete dissolution. PBT-BSA solution can be stored at $4{ }^{\circ} \mathrm{C}$ for $\leq 1$ week.

\section{$70 \%$ ethanol solution}

To prepare 11 of this solution, mix $729 \mathrm{ml}$ of $96 \%$ ethanol with $271 \mathrm{ml}$ of bidistilled water. $70 \%$ ethanol solution can be prepared in advance and stored at $\mathrm{rt}$ for $\leq 2$ months.

$0.2 \mathrm{M}$ Tris- $\mathrm{HCl}(\mathrm{pH}=8.5)$

To prepare $500 \mathrm{ml}$ of this buffer, dissolve $12.114 \mathrm{~g}$ of Trizma base in $350 \mathrm{ml}$ of bidistilled water. Adjust pH with $\mathrm{HCl}$. Complete the final volume to $500 \mathrm{ml}$. $0.2 \mathrm{M}$ Tris- $\mathrm{HCl}$ can be prepared in advance and stored at $\mathrm{rt}$ for $\leq 6$ months.

\section{Antifade mounting medium}

Mix $12 \mathrm{~g}$ of $100 \%$ glycerol with $12 \mathrm{ml}$ of distilled water and add $4.8 \mathrm{~g}$ of Mowiol 4-88. Shake overnight using a magnetic shaker at rt. The next morning, add $24 \mathrm{ml}$ of $0.2 \mathrm{M}$ Tris- $\mathrm{HCl}(\mathrm{pH}=8.5)$ and shake for $10 \mathrm{~min}$ at $50{ }^{\circ} \mathrm{C}$. Place the solution in a $50-\mathrm{ml}$ falcon tube and centrifuge at $5000 \mathrm{~g}$ for $12 \mathrm{~min}$ at 
$4{ }^{\circ} \mathrm{C}$. Take the supernatant and aliquot in 2-ml Eppendorf tubes. This medium can be stored for $\leq 1$ year at $-20{ }^{\circ} \mathrm{C}$ protected from light.

$2 \%$ gelatin-coated glass slides

Dissolve $6 \mathrm{~g}$ of porcine gelatin in $300 \mathrm{ml}$ of hot bidistilled water under shaking in a magnetic shaker. After complete dissolution of the gelatin, add $0.5 \mathrm{~g}$ of $\mathrm{KCr}\left(\mathrm{SO}_{4}\right)_{2}$. Place on a filter paper. Pour $250 \mathrm{ml}$ of the solution in a glass staining jar. Place 10 slides on a holder. Submerge the slides in the gelatin solution for $1 \mathrm{~min}$. Allow the slides to dry overnight before use. Gelatin-coated slides can be stored at rt for $\leq 6$ months.

\section{Equipment setup}

\section{Leica VT-1200S sliding blade vibratome setup}

Place the specimen holder containing the sample (Fig. $2 \mathrm{~g}$ ) into the tray and fill the tray with $0.1 \mathrm{~N} \mathrm{~PB}$ (Fig. 2h). Place the blade into the holder and adjust the sectioning angle. Set up sectioning parameters (speed, section thickness and blade amplitude). For optimally preserved tissue, which has been fixed for $24 \mathrm{~h}$ and embedded in a 10\% sucrose- $4 \%$ agarose solution, a speed of between 1 and $1.3 \mathrm{~mm} / \mathrm{s}$ and amplitude between 1.7 and $1.9 \mathrm{~mm}$ are suitable for obtaining $50-\mu \mathrm{m}$-thick sections. When necessary, reduce sectioning speed and blade vibration (up to a speed of $0.4 \mathrm{~mm} / \mathrm{s}$ and an amplitude of $1.35 \mathrm{~mm}$ ).

\section{Water bath setup}

The water bath should be set to $80^{\circ} \mathrm{C}$ in advance.

\section{Procedure}

\section{Tissue dissection and fixation Timing $24 \mathrm{~h}$}

1 Hippocampal dissection. Immediately after brain extraction (Fig. 2a), separate hemispheres through a mid-sagittal section (Fig. 2b). Next, remove the meninges (Fig. 2c).

2 To isolate the rostro-caudal level of the hippocampus intended to be analyzed (the posterior portion of the anterior hippocampus), first identify extra-hippocampal anatomical cues.

$\triangle$ CRITICAL STEP This is of particular importance to avoid putative anatomical bias caused by hippocampal atrophy and to ensure homogeneity in the location of the sampling region.

3 Identify the posterior poles of both the mammillary bodies (Level 32 in The Human Brain Atlas ${ }^{39}$ ) and the uncus (Level 39 in The Human Brain Atlas ${ }^{39}$ ), to dissect a coronal 1-cm-thick slice of the whole hemisphere at this anatomical level (Fig. 1a).

4 Rapidly dissect on ice a tissue block corresponding to the posterior portion of the anterior hippocampus (Fig. 2d).

5 Tissue fixation. Immediately immerse the hippocampal block in a freshly prepared $4 \%$ PFA fixative solution. Fixation should be limited to $24 \mathrm{~h}$ at $4{ }^{\circ} \mathrm{C}$ for optimal detection of the antibodies shown in Table 1. After fixation completion, wash the hippocampal block (three 30 -s washes) in $0.1 \mathrm{~N} \mathrm{~PB}$ at room temperature.

$\triangle$ CRITICAL STEP Note that different fixation times may result in completely different results with respect to the detection of several proteins ${ }^{9}$. In our initial study, we showed that $4 \%$ PFA fixation times longer than $12 \mathrm{~h}$ require the application of histological pre-treatments on the tissue to allow the detection of several markers of AHN, such as DCX ${ }^{9}$. In addition, it should be noted that the performance of distinct anti-DCX antibodies differs after either 6 or $24 \mathrm{~h}$ in this fixative (Fig. 3). Optimal fixation times when using conditions (e.g., thickness of the tissue block, sectioning method, etc.) that differ from those recommended in the present procedure should be experimentally determined by researchers and validated ${ }^{9}$.

\section{Tissue sectioning Variable timing: 2-3 h per sample}

6 Tissue inclusion. With the help of thin forceps, remove the meninges and blood vessels from the tissue surface.

$\triangle$ CRITICAL STEP These structures are harder than brain parenchyma and may cause tissue damage during sectioning.

7 Prepare the $10 \%$ sucrose- $4 \%$ agarose solution (or thaw an aliquot of stored stock solution). Sucroseagarose is solid at rt. To achieve a liquid consistency, melt the sucrose-agarose in a microwave.

8 Once the sucrose-agarose is liquid, pour a small amount of this solution into an individual well of a 12-well plastic plate. $5-10 \mathrm{ml}$ of solution is sufficient to process one tissue block. Before the sucrose-agarose re-solidifies, place the hippocampal tissue block in the same well. Pour more 
sucrose-agarose solution until it reaches the top of the well. Depending on the tissue block size, 24-, 12- or 6-well plates should be used (Fig. 2e).

9 Place the plate on ice and gently re-immerse the hippocampal block into the sucrose-agarose as it tends to float for the first $2 \mathrm{~min}$.

10 Wait until the sucrose-agarose has completely solidified again (Fig. 2f).

11 Extract the sucrose-agarose-embedded hippocampal block from the well and sculpt a cubic block, ensuring that at least 2-3 mm of sucrose-agarose surrounds the hippocampal tissue block in all the dimensions (Fig. 2g).

12 Tissue sectioning on a sliding-blade vibratome. Fix the agarose-sucrose of the tissue block to the specimen holder using cyanoacrylate glue (Fig. 2g). Wait a few minutes until the cyanoacrylate is no longer transparent. Place the specimen holder in the vibratome tray, which should be filled with $0.1 \mathrm{~N} \mathrm{~PB}$ (Fig. $2 \mathrm{~h}$ ). $\triangle$ CRITICAL STEP The instructions included in this section are valid for a Leica VT-1200S sliding blade vibratome. The method should be adjusted if a different sliding blade vibratome is used.

13 Adjust sectioning parameters to optimal conditions depending on the quality and robustness of the tissue (Fig. 2h-i).

$\triangle$ CRITICAL STEP Optimal sectioning parameters are influenced by the qualities of the tissue being sectioned.

\section{? TROUBLESHOOTING}

14 With the help of a soft brush (Fig. 2j), collect sections on individual wells of 96-well plastic plates filled with $0.1 \mathrm{~N} \mathrm{~PB}$ solution. Keep plates on ice to ensure better preservation of the tissue.

15 If you wish, reconstruct series of sections following stereological sampling criteria.

16 After sectioning, transfer brain sections to plates filled with cryopreservative solution and immediately store at $-20{ }^{\circ} \mathrm{C}$.

DAUSE POINT Sections can be stored in this medium for several years, without perceiving any decrease in the quality of the tissue or failure in detecting antibody signal.

17 Before starting IHC, rinse slices in $0.1 \mathrm{~N} \mathrm{~PB}$ for $30 \mathrm{~min}$ at $\mathrm{rt}$ (three $\times 10$-min rinses under gentle shaking).

\section{IHC Timing 6 days}

$18 \mathrm{NaBH}_{4}$ incubation. Incubate sections in a $0.5 \% \mathrm{NaBH}_{4}$ solution for $30 \mathrm{~min}$. One or two sections that belong to the same patient can be placed inside each well in 24 -well plastic plates. Cover the plate with a lid and place the plate on an orbital shaker under gentle shaking at rt. The formation of small bubbles is usually observed (Fig. 2k).

$\triangle$ CRITICAL STEP This step critically influences the results of the IHC (Fig. 4).

19 Wash the sections five times with PBT-BSA (30-s washes).

$20 H C$-AR. Fill $10-\mathrm{ml}$ glass scintillation vials with $5 \mathrm{ml}$ of a $1 \times$ citrate buffer $(\mathrm{pH} 6.0$ ) antigen retrieval solution preheated at $\sim 90^{\circ} \mathrm{C}$ (Fig. 21).

21 Place one to four sections belonging to the same patient in each scintillation vial and close vials. Do not seal the vials so as to prevent any undesired increase of pressure during microwaving (Fig. 2l).

22 Expose vials to five to six brief (10- to 20-s) cycles of microwave heating (in a standard $800-\mathrm{W}$ kitchen microwave, the highest power should be used). To prevent tissue damage, do not boil the liquid. If the liquid does boil, the microwave cycle should be aborted immediately. Between cycles, wait a few seconds before starting the next cycle. Depending on the power of the microwave used, the number and length of cycles may need to be adjusted. Microwaving should be repeated until the borders of the sections start to become slightly curved, similar to the appearance of the borders indicated with red arrows in Fig. $2 \mathrm{~m}$. Once the borders are curved, there is no need to microwave further. Excessive folding of the borders should be avoided (blue arrows in Fig. $2 \mathrm{n}$ ) to prevent tissue damage, high background and lack of signal specificity (Fig. 4c).

? TROUBLESHOOTING

$\triangle$ CRITICAL STEP Performing this step critically influences the results of the IHC (Fig. 4). Moreover, the intensity of this treatment should be adjusted to prevent tissue damage.

23 After completing the microwaving step, tightly close and immerse the vials in an $80^{\circ} \mathrm{C}$ water bath for $20 \mathrm{~min}$. Ensure that the water from the bath does not enter the vials (Fig. 2o,p).

? TROUBLESHOOTING

24 Leave the closed vials at $\mathrm{rt}$ for an additional $20 \mathrm{~min}$.

25 Remove sections from the vials with the help of a soft brush and rinse them five times in $0.1 \mathrm{~N}$ PB (30-s washes) after completion of HC-AR. 
26 Primary antibody incubation. Place the appropriate primary antibody diluted in PBT-BSA solution into each well of a 24-well plastic plate. Add sections and ensure that these are floating freely. A final volume of 350-400 $\mu \mathrm{l}$ per well is adequate to incubate up to two $\left(1-\mathrm{cm}^{2}\right)$ sections per well in these plates. For a higher number of sections, the final incubation volume should be increased accordingly. Incubate sections with primary antibodies for 5 days at $4{ }^{\circ} \mathrm{C}$ under gentle shaking.

$\triangle$ CRITICAL STEP This incubation time has been shown to be optimal for the antibodies listed in Table 1 and for 50- $\mu$ m vibratome-sectioned human brain samples. However, some antibodies also show good performance in shorter incubations (Fig. 4d). Optimal incubation time and conditions should be determined experimentally.

? TROUBLESHOOTING

27 Wash sections five times with PBT-BSA solution (30-s washes).

28 Secondary antibody incubation. Incubate the sections with fluorescent secondary antibodies, diluted in PBT-BSA solution, overnight at $4^{\circ} \mathrm{C}$ under gentle shaking. To perform this step, 24-well plastic plates and a final incubation volume of $500 \mu \mathrm{l}$ for up to three sections per well can be used. Note that an overnight incubation has been shown to be optimal for the antibodies listed in Table 2 and for $50-\mu \mathrm{m}$ vibratome-sectioned human brain samples. However, the optimal incubation time and conditions should be experimentally tested for samples processed in a different manner.

$\triangle$ CRITICAL STEP From this step onward, sections should be protected from light. To this end, aluminum foil can be used to cover plates.

29 Wash sections three times with $0.1 \mathrm{~N} \mathrm{~PB}$ (30-s washes).

30 DAPI incubation. (Optional) To counterstain sections for $10 \mathrm{~min}$ with DAPI (1:5,000 (vol/vol) in $0.1 \mathrm{~N} \mathrm{~PB}$ ) to label cell nuclei, incubate free-floating sections with DAPI in 24-well plastic plates under gentle shaking at rt. 24-well plastic plates and a final incubation volume of $500 \mu$ for up to three sections per well can be used.

31 Wash sections three times with $0.1 \mathrm{~N}$ PB (30-s washes) at rt.

32 Autofluorescence elimination step. Immerse sections in $1 \mathrm{ml}$ of $70 \%$ ethanol solution for $5 \mathrm{~min}$ under gentle shaking in 24-well plastic plates. An incubation volume of $500 \mu \mathrm{l}$ for up to three sections per well can be used.

33 Incubate sections in undiluted autofluorescence eliminator reagent for $5 \mathrm{~min}$ under vigorous shaking to prevent excessive reagent precipitation. It should be noted that this reagent is a commercial preparation of sudan black diluted in ethanol ${ }^{9} .200-300 \mu \mathrm{l}$ of reagent should be poured over the sections until they are completely covered. Note that autofluorescence eliminator solution is opaque black. Thus, brain sections are subsequently stained metachromatic black.

$\triangle$ CRITICAL STEP Performing this step critically influences the results of the IHC (Fig. 5). Moreover, the intensity of this treatment should be adjusted to the native amount of autofluorescence of the tissue.

? TROUBLESHOOTING

34 Wash sections three times in $1 \mathrm{ml}$ of $70 \%$ ethanol solution (1-min washes under vigorous shaking). Ensure that most of the precipitated aggregates of the autofluorescence eliminator solution are removed after washing.

35 Wash sections three times in $1 \mathrm{ml}$ of $0.1 \mathrm{~N} \mathrm{~PB}$ (30-s washes) at rt under gentle shaking.

36 Section mounting. Mount sections on $2 \%$ gelatin-coated glass slides. Either commercial or noncommercial mounting media can be used to embed the sections, although we use a non-commercial antifade mounting medium for this purpose. Apply a coverslip and allow the preparations to dry protected from light. Carefully clean away excess mounting medium.

DAUSE POINT Slides should be stored at $\mathrm{rt}$ and protected from light in opaque microscope slide cages. Depending on the primary and secondary antibodies used, fluorescence fading may occur over time. Thus, to ensure homogeneity and to prevent excessive fluorescence intensity decay, it is recommended that confocal images be acquired within 1 month of section mounting.

\section{Confocal microscope image acquisition Variable timing}

37 Place the glass slide on the confocal microscope. Use the epifluorescence function of the microscope and a low-magnification dry objective to locate the region of interest, namely the DG. This region is easily identifiable by the high density of granule cells. Use DAPI to identify the area of interest. Select the lowest intensity of the fluorescence lamp to prevent fluorescence quenching.

38 Focus on the GCL by using an immersion oil $40 \times$ objective. Use the DAPI channel to select the sampling zone. 
39 Adjust laser power, gain and acquisition setting parameters for each channel. Define the laser power as the minimum value necessary to visualize the signal. Subtract background or increase the number of laser passes when necessary.

? TROUBLESHOOTING

40 Define the $\mathrm{z}$-step size in the software. For $\mathrm{DCX}^{+}$cell counts, a $1-\mu \mathrm{m}$ z-interval is suitable when using a Plan-Apochromat 40×/1.3 Oil DIC (UV) VIS-IR M27 immersion oil objective (0.8 zoom; XY dimensions: $199.66 \mu \mathrm{m} \times 199.66 \mu \mathrm{m}$; pinhole dimensions: 0.9 Airy units; thickness of the optical section: $0.7 \mu \mathrm{m}$ ) in a LSM800 Zeiss confocal microscope. This parameter should be optimally adjusted depending on the microscope and objective used or the parameters to be analyzed.

41 Define the $\mathrm{z}$-stack thickness. Acquire a variable number of stacks of images per subject. Note that the number of stacks needed should be determined and adapted to the parameters of interest ${ }^{33}$. Stacks of images should be obtained at randomly selected locations along the DG. Researchers are strongly encouraged to use the DAPI channel to manually select these locations, and they should be blinded to experimental conditions during image acquisition and analysis.

\section{Image analysis Variable timing}

42 Determination of the reference volume. Note that the method used to calculate the reference volume will depend on the type of dissector used. Trace the GCL on the DAPI channel of the z-projection of each confocal stack of images to delineate the area inside of which $\mathrm{DCX}^{+}$cells will be counted. Draw and measure the area of this structure using the freehand drawing tool of Fiji. Multiply this area by the z-thickness of the stack to calculate the reference volume inside of which cells will be counted. The same histological preparations used to count $\mathrm{DCX}^{+}$cells can be used to determine the total numbers of other cell types. In this case, images acquired should be adapted to the cell density and distribution of the cell population of interest. For example, to count the number of $\mathrm{NeuN}^{+}$ mature DGCs (Fig. 6b), use high-power magnification images that include only a small proportion of the GCL and calculate the reference volume by multiplying the $\mathrm{X}, \mathrm{Y}$ and $\mathrm{Z}$ dimensions of the stack, as previously described ${ }^{9,33}$.

43 Stereological cell counts. Estimate cell density using the physical dissector method adapted to confocal microscopy, as previously described ${ }^{33}$. To do this, count the number of cells of interest inside the reference volume on individual planes. In Fig. 6c,d, each cell is marked with a number on the plane in which it is observed the first time. Subsequently, an " $\mathrm{x}$ " is placed on the same location of the next planes to avoid counting the same cell multiple times. Count $\mathrm{DCX}^{+}$cells that are located inside the GCL only (note that the images acquired should include the GCL and a small portion of the molecular layer (ML) and hilus $(\mathrm{H})$ ). Divide this number of cells by the reference volume and calculate cell density (number of cells $/ \mathrm{mm}^{3}$ ) (Fig. 6e).

$\triangle$ CRITICAL STEP Prior to performing cell counts, (Fig. 6c,d), clearly define the criteria that will be used to unambiguously identify positive cells. Drawing up a list of these criteria is strongly recommended. These criteria may include comparison to previously published and validated data. When there are no available data or novel markers are intended to be identified, some of the following criteria may be used as a reference. Cell morphology should be clearly and unambiguously identifiable, and cells showing apoptotic characteristics on the DAPI channel or autofluorescence in any of the channels acquired should be discarded (Fig. 5).

44 Additional analyses. Carry out any additional analyses that might be required, for example, colocalization analyses and quantification of the expression of cell markers (option A) or morphometric determinations (option B).

(A) Colocalization analyses and quantification of the expression of cell markers

(i) Perform colocalization analyses. Use a Plan-Apochromat $63 \times / 1.40$ Oil DIC M27 immersion oil objective ( 2.2 zoom, XY dimensions: $46 \mu \mathrm{m} \times 46 \mu \mathrm{m}$; z-interval: $0.5 \mu \mathrm{m}$; pinhole dimensions: 0.9 Airy units; thickness of the optical section: $0.5 \mu \mathrm{m}$ ) to acquire high-power magnification images that include all the channels of the soma of the cell of interest. Use one of the markers for reference and analyze colocalization by determining the percentage of double- or triple-labeled cells for other markers (Fig. 6f).

(ii) Once the cell population of interest has been identified, determine the expression of distinct cell markers by measuring fluorescence intensity (Fig. 6j). Draw the cell contour manually and then measure the fluorescence intensity for any of the additional markers in Fiji. An example of the quantification of NeuN expression in $\mathrm{DCX}^{+}$and $\mathrm{DCX}^{-}$cells is shown in Fig. 6g,j. It can be observed that NeuN expression is lower in the former. 


\section{(B) Morphometric determinations}

$\triangle$ CRITICAL Various parameters, such as cell area (Fig. 6k), position of the cells within the structure of interest (Fig. 6h) and number of neurites (Fig. 6i), among others, can be measured on the images acquired for cell density estimation. Some examples are described in this section.

(i) To determine the position of the cells within the GCL, identify the hilar and molecular borders of this structure (Fig. $6 \mathrm{~g}, \mathrm{~h}$ ). Determine the number of cells placed in subregions of the structure or relative position?

(ii) Analyze the number and orientation of neurites (Fig. 6i) by calculating the percentage of cells in which one, two, three or four neurites are identified. To identify the orientation of these neurites, measure the angle between the hilar border and each individual neurite?

(iii) To determine the area of the soma (Fig. 6k), obtain z-stacks of images under an oilimmersion $63 \times$ objective and draw the soma contour on the plane in which it is maximal and continuous around the nucleus. Measure the area using Fiji software ${ }^{9}$. In Fig. 6k, the determination of the area of $\mathrm{DCX}^{+} /$Calbindin $(\mathrm{CB})^{+}$and $\mathrm{DCX}^{-} / \mathrm{CB}^{+}$cells is shown. As can be observed, this area is smaller in $\mathrm{DCX}^{+}$cells.

\section{Troubleshooting}

Troubleshooting advice can be found in Table 4 .

Table 4 | Troubleshooting advice

\begin{tabular}{lll} 
Step & Problem & Possible reason \\
\hline 13 & Low robustness of the tissue \\
$\begin{array}{l}\text { Orientation of the block is not } \\
\text { correct }\end{array}$ & $\begin{array}{l}\text { Fixation time was too short } \\
\text { Cyanoacrylate surface was not flat when fixing } \\
\text { the agarose block }\end{array}$
\end{tabular}

Sections are torn during sectioning

Section borders are not curved after HC-AR

Sections are excessively folded

Sections are damaged during High intensity of HC-AR HC-AR
There are meninges or blood vessels on the surface of the tissue block. These structures are much harder than the tissue and may cause tissue damage when touched by the blade

Sectioning parameters are not correctly adjusted to the quality and robustness of the tissue

The block is not correctly fixed to the vibratome bracket and moves during sectioning

Low intensity of HC-AR

High intensity of HC-AR

Quality of the tissue is suboptimal

\section{Solution}

Increase fixation time

Remove the agarose-sucrose block from the bracket. Carefully remove the cyanoacrylate when completely solidified by using a scalpel. Fix the block again with fresh cyanoacrylate and correct the angle of the block.

Alternatively, adjust the surface of the agarose block to achieve a different angle

Carefully remove the meninges or blood vessels with the help of thin forceps. Be careful not to damage adjacent tissue

Progressively reduce blade speed or amplitude. Both parameters should be decreased in parallel

Increase sectioning thickness to $60 \mu \mathrm{m}$ in very extreme cases

Remove the agarose-sucrose block from the bracket. Carefully remove the cyanoacrylate when completely solidified with the help of a scalpel. Fix the block again with fresh cyanoacrylate

Increase microwave power or number of cycles

Consider the possibility of setting up an alternative antigen retrieval method (i.e., a commercial pressurebased system)

Reduce microwave power or number of cycles

Consider the possibility of setting-up an alternative antigen retrieval method (i.e., a commercial pressurebased system)

Reduce microwave power or number of cycles

Consider the possibility of setting-up an alternative antigen retrieval method (i.e., a commercial pressurebased system)

Revise tissue preservation methods

Table continued 
Table 4 (continued)

\begin{tabular}{|c|c|c|c|}
\hline Step & Problem & Possible reason & Solution \\
\hline \multirow[t]{2}{*}{23} & \multirow{2}{*}{$\begin{array}{l}\text { Water from the bath enters } \\
\text { the scintillation vials during } \\
\text { incubation at } 80^{\circ} \mathrm{C}\end{array}$} & Vials are not tightly sealed & Seal vials tightly \\
\hline & & $\begin{array}{l}\text { The level of the water is above the upper part of } \\
\text { the scintillation vials }\end{array}$ & $\begin{array}{l}\text { Place scintillation vials inside a glass beaker } \\
\text { containing enough water at } 80{ }^{\circ} \mathrm{C} \text { to cover the liquid } \\
\text { inside the scintillation vials. Place a heavy item on top } \\
\text { of the beaker with the scintillation vials to push it to } \\
\text { the bottom of the bath (impeding water from the bath } \\
\text { from entering the glass beaker) }\end{array}$ \\
\hline \multirow[t]{11}{*}{26} & \multirow{3}{*}{$\begin{array}{l}\text { Lack of signal when using } \\
\text { previously validated } \\
\text { antibodies }\end{array}$} & Fixation time prevents protein detection & Vary fixation time \\
\hline & & HC-AR intensity is too low & Increase microwave power or number of cycles \\
\hline & & Antibody may have stopped working & Test it on positive control tissue \\
\hline & $\begin{array}{l}\text { Lack of signal when using } \\
\text { non-previously validated } \\
\text { antibodies }\end{array}$ & Antibody may not work in that type of tissue & Test it on positive control tissue \\
\hline & \multirow[t]{4}{*}{ High background } & \multirow{2}{*}{$\begin{array}{l}\text { The concentration of the antibody may be } \\
\text { too high }\end{array}$} & Reduce antibody concentration \\
\hline & & & Increase the concentration of BSA \\
\hline & & Incubation time may be excessive & Reduce incubation time \\
\hline & & $\begin{array}{l}\text { Intensity of the autofluorescence elimination step } \\
\text { may be too low }\end{array}$ & $\begin{array}{l}\text { Increase incubation time with autofluorescence } \\
\text { eliminator reagent }\end{array}$ \\
\hline & \multirow{3}{*}{$\begin{array}{l}\text { Signal is specific, but intensity } \\
\text { is too low }\end{array}$} & Low concentration of primary antibodies & Increase primary antibody concentration \\
\hline & & Insufficient incubation time & Increase incubation time \\
\hline & & $\begin{array}{l}\text { Excessive intensity of the autofluorescence } \\
\text { elimination step }\end{array}$ & $\begin{array}{l}\text { Reduce incubation time with autofluorescence } \\
\text { eliminator reagent }\end{array}$ \\
\hline 33 & Autofluorescence is too high & $\begin{array}{l}\text { Low intensity of the autofluorescence } \\
\text { elimination step }\end{array}$ & $\begin{array}{l}\text { Increase incubation time with autofluorescence } \\
\text { eliminator reagent }\end{array}$ \\
\hline \multirow[t]{10}{*}{39} & $\begin{array}{l}\text { Fluorescence is quenched } \\
\text { during imaging parameter } \\
\text { setup or during sample } \\
\text { observation }\end{array}$ & $\begin{array}{l}\text { Excessive exposure of the sample to } \\
\text { fluorescence light }\end{array}$ & $\begin{array}{l}\text { Reduce the laser power and increase gain during } \\
\text { parameter setup. Reduce the intensity of the } \\
\text { fluorescence lamp or specimen observation time }\end{array}$ \\
\hline & \multirow{3}{*}{$\begin{array}{l}\text { Fluorescence is quenched } \\
\text { during image acquisition }\end{array}$} & Excessive laser power & Reduce laser power and increase gain when possible \\
\hline & & Excessive number of laser passes & Reduce the number of laser passes \\
\hline & & Excessively high image resolution & Reduce image resolution \\
\hline & \multirow[t]{2}{*}{ High background } & \multirow[t]{2}{*}{ Background is not adequately subtracted } & Subtract higher background \\
\hline & & & $\begin{array}{l}\text { Increase the number of laser passes to increase image } \\
\text { cleanliness }\end{array}$ \\
\hline & \multirow[t]{4}{*}{ Low image quality } & IHC conditions are not correctly set up & $\begin{array}{l}\text { User should look at the earlier guidance for steps } 22 \text {, } \\
23,26 \text { and } 33\end{array}$ \\
\hline & & Low number of laser passes & Increase the number of laser passes \\
\hline & & Low image resolution & Increase image resolution \\
\hline & & Excessive image acquisition speed & Reduce image acquisition speed \\
\hline
\end{tabular}

Step of the procedure, problem encountered, possible reasons, and advice are shown.

Steps 1-5, tissue dissection and fixation: $24 \mathrm{~h}$

1-4, hippocampal dissection: 15 min per sample

5, tissue fixation: $24 \mathrm{~h}$

Steps 6-17, tissue sectioning: $2-3 \mathrm{~h}$ per sample

6-11, tissue inclusion: $20-30 \mathrm{~min}$

$12-17$, tissue sectioning on a sliding-blade vibratome: $1-2.5 \mathrm{~h}$ per sample

Steps 18-12, IHC: 6 days

18-19, $\mathrm{NaBH}_{4}$ incubation: $30 \mathrm{~min}$

20-25, HC-AR: $\sim 45 \min$ to $1 \mathrm{~h}$

26-27, primary antibody incubation: 5 days

28-29, secondary antibody incubation: 1 day

30-31, DAPI incubation: $10 \mathrm{~min}$ 
32-35, autofluorescence elimination step: $\sim 20 \mathrm{~min}$

36, section mounting: 5-10 min per sample

Pausepoint Storage: variable timing

Steps 37-41, confocal microscope image acquisition: variable timing

Steps $42-44$, image analysis: variable timing

The strict criteria we followed to develop the current protocol included obtaining post-mortem human samples of the highest possible quality, collected under tightly controlled conditions, plus the optimization of tissue processing and histological procedures for the study of AHN in human tissue. By applying a series of simple and inexpensive tissue treatments, we have developed a reliable method that allows unambiguous identification of an abundant population of immature neurons in the human hippocampus until the 10th decade of life ${ }^{9}$.

By using this protocol, quantitative data regarding cell density or total numbers of cells, colocalization analyses and morphometric determinations can be reliably obtained from post-mortem human brain samples (Figs. 3-6). Our methodology can be used to improve tissue sample collection and processing and to perform IHC and cell counts in a reliable manner. Given our previous observation that parameters, such as the type of fixative used and fixation time, dramatically influence the detection of markers of $\mathrm{AHN}$ in human brain tissue ${ }^{9}$, we suggest that several pilot experiments be performed to finely adjust IHC parameters to the detection of any (already known or newly described) given marker in human brain tissue. We also provide examples of how slight variations in critical steps throughout the procedure influence the outcomes of IHC performed in this tissue. The observation that variations in these conditions can yield completely opposing results $^{3,9-11,14}$ should be taken into account by future studies seeking to expand our current knowledge of AHN in humans.

\section{Reporting Summary}

Further information on research design is available in the Nature Research Reporting Summary linked to this article.

\section{Data availability}

All data and/or analyses generated have been included in the paper.

\section{References}

1. Altman, J. Autoradiographic investigation of cell proliferation in the brains of rats and cats. Anat. Rec. 145, 573-591 (1963).

2. Kohler, S. J., Williams, N. I., Stanton, G. B., Cameron, J. L. \& Greenough, W. T. Maturation time of new granule cells in the dentate gyrus of adult macaque monkeys exceeds six months. Proc. Natl Acad. Sci. USA 108, 10326-10331 (2011).

3. Eriksson, P. S. et al. Neurogenesis in the adult human hippocampus. Nat. Med. 4, 1313-1317 (1998).

4. Sahay, A. et al. Increasing adult hippocampal neurogenesis is sufficient to improve pattern separation. Nature 472, 466-470 (2011).

5. Zhao, C., Teng, E. M., Summers, R. G. Jr., Ming, G. L. \& Gage, F. H. Distinct morphological stages of dentate granule neuron maturation in the adult mouse hippocampus. J. Neurosci. 26, 3-11 (2006).

6. Bischofberger, J. Young and excitable: new neurons in memory networks. Nat. Neurosci. 10, 273-275 (2007).

7. Marin-Burgin, A., Mongiat, L. A., Pardi, M. B. \& Schinder, A. F. Unique processing during a period of high excitation/inhibition balance in adult-born neurons. Science 335, 1238-1242 (2012).

8. Braak, H. \& Braak, E. [Morphology of Alzheimer disease]. Fortschr. Med. 108, 621-624 (1990).

9. Moreno-Jimenez, E. P. et al. Adult hippocampal neurogenesis is abundant in neurologically healthy subjects and drops sharply in patients with Alzheimer's disease. Nat. Med. 25, 554-560 (2019).

10. Knoth, R. et al. Murine features of neurogenesis in the human hippocampus across the lifespan from 0 to 100 years. PLOS One 5, e8809 (2010).

11. Boldrini, M. et al. Human hippocampal neurogenesis persists throughout aging. Cell Stem Cell 22, 589-599.e5 (2018).

12. Tobin, M. K. et al. Human hippocampal neurogenesis persists in aged adults and Alzheimer's disease patients. Cell Stem Cell 24, 974-982.e3 (2019).

13. Sorrells, S. F. et al. Human hippocampal neurogenesis drops sharply in children to undetectable levels in adults. Nature 555, 377-381 (2018). 
14. Cipriani, S. et al. Hippocampal radial glial subtypes and their neurogenic potential in human fetuses and healthy and Alzheimer's disease adults. Cereb. Cortex 28, 2458-2478 (2018).

15. Evers, P., Uylings, H. B. \& Suurmeijer, A. J. Antigen retrieval in formaldehyde-fixed human brain tissue. Methods 15, 133-140 (1998).

16. Dowson, J. H. The evaluation of autofluorescence emission spectra derived from neuronal lipopigment. J. Microsc. 128, 261-270 (1982).

17. Spalding, K. L. et al. Dynamics of hippocampal neurogenesis in adult humans. Cell 153, 1219-1227 (2013).

18. Tartt, A. N. et al. Considerations for assessing the extent of hippocampal neurogenesis in the adult and aging human brain. Cell Stem Cell 23, 782-783 (2018).

19. Manganas, L. N. et al. Magnetic resonance spectroscopy identifies neural progenitor cells in the live human brain. Science 318, 980-985 (2007).

20. Greenberg, D. A. \& Jin, K. Neurodegeneration and neurogenesis: focus on Alzheimer's disease. Curr. Alzheimer Res. 3, 25-28 (2006).

21. Spalding, K. L., Bhardwaj, R. D., Buchholz, B. A., Druid, H. \& Frisen, J. Retrospective birth dating of cells in humans. Cell 122, 133-143 (2005).

22. Bao, A. M. \& Swaab, D. F. The art of matching brain tissue from patients and controls for postmortem research. Handb. Clin. Neurol. 150, 197-217 (2018).

23. Boekhoorn, K., Joels, M. \& Lucassen, P. J. Increased proliferation reflects glial and vascular-associated changes, but not neurogenesis in the presenile Alzheimer hippocampus. Neurobiol. Dis. 24, 1-14 (2006).

24. Braak, H., Alafuzoff, I., Arzberger, T., Kretzschmar, H. \& Del Tredici, K. Staging of Alzheimer diseaseassociated neurofibrillary pathology using paraffin sections and immunocytochemistry. Acta Neuropathol. 112, 389-404 (2006).

25. Thavarajah, R., Mudimbaimannar, V. K., Elizabeth, J., Rao, U. K. \& Ranganathan, K. Chemical and physical basics of routine formaldehyde fixation. J. Oral. Maxillofac. Pathol. 16, 400-405 (2012).

26. Plumpe, T. et al. Variability of doublecortin-associated dendrite maturation in adult hippocampal neurogenesis is independent of the regulation of precursor cell proliferation. BMC Neurosci. 7, 77 (2006).

27. Gleeson, J. G., Lin, P. T., Flanagan, L. A. \& Walsh, C. A. Doublecortin is a microtubule-associated protein and is expressed widely by migrating neurons. Neuron 23, 257-271 (1999).

28. Pikkarainen, M., Martikainen, P. \& Alafuzoff, I. The effect of prolonged fixation time on immunohistochemical staining of common neurodegenerative disease markers. J. Neuropathol. Exp. Neurol. 69, 40-52 (2010).

29. Axthelm, M. K. \& Krakowka, S. Immunocytochemical methods for demonstrating canine distemper virus antigen in aldehyde-fixed paraffin-embedded tissue. J. Virol. Methods 13, 215-229 (1986).

30. Guntern, R., Vallet, P. G., Bouras, C. \& Constantinidis, J. An improved immunohistostaining procedure for peptides in human brain. Experientia 45, 159-161 (1989).

31. Leibnitz, L. \& Wunscher, W. [The life-long deposition of intraneuronal lipofuscin in various sections of the human brain]. Anat. Anz. 121, 132-140 (1967).

32. Nishioka, N., Takahata, N. \& Iizuka, R. Histochemical studies on the lipo-pigments in the nerve cells. A comparison with lipofuscin and ceroid pigment. Acta Neuropathol. 11, 174-181 (1968).

33. Llorens-Martin, M., Torres-Aleman, I. \& Trejo, J. L. Pronounced individual variation in the response to the stimulatory action of exercise on immature hippocampal neurons. Hippocampus 16, 480-490 (2006).

34. Gundersen, H. J. Stereology of arbitrary particles. A review of unbiased number and size estimators and the presentation of some new ones, in memory of William R. Thompson. J. Microsc. 143, (3-45 (1986).

35. Bendtsen, T. F. \& Nyengaard, J. R. Unbiased estimation of particle number using sections-an historical perspective with special reference to the stereology of glomeruli. J. Microsc. 153, 93-102 (1989).

36. Howell, K., Hopkins, N. \& McLoughlin, P. Combined confocal microscopy and stereology: a highly efficient and unbiased approach to quantitative structural measurement in tissues. Exp. Physiol. 87, 747-756 (2002).

37. Pallas-Bazarra, $\mathrm{N}$. et al. Novel function of Tau in regulating the effects of external stimuli on adult hippocampal neurogenesis. EMBO J. 35, 1417-1436 (2016).

38. Martinez-Martin, P. \& Avila, J. Alzheimer Center Reina Sofia Foundation: fighting the disease and providing overall solutions. J. Alzheimers Dis. 21, 337-348 (2016).

39. Mai, J., Majtanik, M. \& Paxinos, G. Atlas of the Human Brain 4th edn (Academic Press, 2015).

\section{Acknowledgements}

The authors would like to thank the patients and families for generously donating brain samples. Moreover, they would like to thank Izaskun Rodal and Laura Saiz for help with human sample extraction and processing, and Esther García, Raquel Cuadros and the confocal microscopy facility of the CBMSO for technical assistance. The authors are grateful to Prof. Gleeson for providing an antidoublecortin antibody. This study was supported by the following: the Spanish Ministry of Economy and Competitiveness (SAF-201782185-R and RYC-2015-171899 (M.L.-M.); SAF-2014-53040-P (J.A.)); The Alzheimer's Association (2015-NIRG-340709 and AARG-17528125 (M.L.-M.)); The Association for Frontotemporal Degeneration (2016 Basic Science Pilot Grant Award (M.L.-M.)); the Comunidad de Madrid (PEJD-2017-PRE/BMD-3439 (M.L.-M.)); and the Center for Networked Biomedical Research on Neurodegenerative Diseases (CIBERNED, Spain) (J.A.). Institutional grants from the Fundación Ramón Areces and Banco de Santander to CBMSO are also acknowledged. The salary of E.P.M.-J. was supported by a Comunidad de Madrid researcher contract (PEJD-2017-PRE/BMD-3439). The salary of J.T.-R. was supported by a Universidad Autónoma de Madrid Doctorate fellowship (FPI-UAM 2017 program). The salary of M. F.-G. was supported by a Formación de personal Investigador (FPI) contract, associated with the SAF-2017-82185-R grant (M.L.-M.), supported by the Spanish Ministry for Economy and Competitiveness (PRE2018-085233). The salary of E.P.M.-J. was supported by a Fundación Tatiana Pérez de Guzmán el Bueno Doctorate on Neuroscience Fellowship. 


\section{Author contributions}

M.F.-G., J.T.-R., E.P.M.-J. and M.L.-M. designed and conceived the study. A.R. provided materials and performed the autopsies. M.F.-G., J.T.-R., E.P.M.-J. and M.L.-M. performed experiments and analyzed the data. M.L.-M. wrote the manuscript. J.A. and M.L.-M. obtained funding. All authors critically discussed the data and revised the final version of the manuscript.

\section{Competing interests}

The authors declare no competing interests.

\section{Additional information}

Supplementary information is available for this paper at https://doi.org/10.1038/s41596-019-0267-y.

Correspondence and requests for materials should be addressed to M.L-M.

Peer review information Nature Protocols thanks Josef Bischofberger and the other, anonymous, reviewer(s) for their contribution to the peer review of this work.

Reprints and permissions information is available at www.nature.com/reprints.

Publisher's note Springer Nature remains neutral with regard to jurisdictional claims in published maps and institutional affiliations.

Received: 11 August 2019; Accepted: 30 October 2019;

Published online: 8 January 2020

\section{Related link}

Key references using this protocol

Moreno-Jiménez, E.P. et al. Nat. Med. 25, 554-560 (2019): https://doi.org/10.1038/s41591-019-0375-9 


\section{Reporting Summary}

Nature Research wishes to improve the reproducibility of the work that we publish. This form provides structure for consistency and transparency in reporting. For further information on Nature Research policies, see Authors \& Referees and the Editorial Policy Checklist.

\section{Statistics}

For all statistical analyses, confirm that the following items are present in the figure legend, table legend, main text, or Methods section.

n/a $\mid$ Confirmed

$\square$ \The exact sample size $(n)$ for each experimental group/condition, given as a discrete number and unit of measurement

$\square$ \A statement on whether measurements were taken from distinct samples or whether the same sample was measured repeatedly

The statistical test(s) used AND whether they are one- or two-sided

$\square$ Only common tests should be described solely by name; describe more complex techniques in the Methods section.

$\bigotimes \square$ A description of all covariates tested

Х $\square$ A description of any assumptions or corrections, such as tests of normality and adjustment for multiple comparisons

$\square$ A full description of the statistical parameters including central tendency (e.g. means) or other basic estimates (e.g. regression coefficient)

AND variation (e.g. standard deviation) or associated estimates of uncertainty (e.g. confidence intervals)

For null hypothesis testing, the test statistic (e.g. $F, t, r$ ) with confidence intervals, effect sizes, degrees of freedom and $P$ value noted

$\triangle \square$ Give $P$ values as exact values whenever suitable.

Х $\square$ For Bayesian analysis, information on the choice of priors and Markov chain Monte Carlo settings

Х $\square$ For hierarchical and complex designs, identification of the appropriate level for tests and full reporting of outcomes

Х $\square$ Estimates of effect sizes (e.g. Cohen's $d$, Pearson's $r$ ), indicating how they were calculated

Our web collection on statistics for biologists contains articles on many of the points above.

\section{Software and code}

Policy information about availability of computer code

Data collection Fiji (Image 64 bits 1.51s) was used to analyze confocal images

Data analysis GraphPad Prism 5 was used to perform statistical tests

For manuscripts utilizing custom algorithms or software that are central to the research but not yet described in published literature, software must be made available to editors/reviewers. We strongly encourage code deposition in a community repository (e.g. GitHub). See the Nature Research guidelines for submitting code \& software for further information.

\section{Data}

Policy information about availability of data

All manuscripts must include a data availability statement. This statement should provide the following information, where applicable:

- Accession codes, unique identifiers, or web links for publicly available datasets

- A list of figures that have associated raw data

- A description of any restrictions on data availability

All data and/or analyses generated have been included in the manuscript.

\section{Field-specific reporting}

Please select the one below that is the best fit for your research. If you are not sure, read the appropriate sections before making your selection. $\bigotimes$ Life sciences $\quad \square$ Behavioural \& social sciences $\square$ Ecological, evolutionary \& environmental sciences 


\section{Life sciences study design}

All studies must disclose on these points even when the disclosure is negative.

Sample size Sample size was not predicted. They were chosen based on previous literature. We have used a collection of human samples composed by 13 healthy control individuals.

Data exclusions No data were excluded

Replication Experimental findings were reproduced in at least three independent experiments. All replications were successful.

Randomization Subjects were classified on the basis of neurological and neuropathological examination. Specifically, Braak-Tau stage was used for classification purposes.

Blinding

Investigators were blinded to group allocation when processing the tissue, performing cell counts or during confocal image acquisition.

\section{Reporting for specific materials, systems and methods}

We require information from authors about some types of materials, experimental systems and methods used in many studies. Here, indicate whether each material, system or method listed is relevant to your study. If you are not sure if a list item applies to your research, read the appropriate section before selecting a response.

Materials \& experimental systems

\begin{tabular}{l|l}
\hline Involved in the study \\
$\square$ Antibodies \\
$\square$ Eukaryotic cell lines \\
$\square$ Palaeontology \\
$\square$ Animals and other organisms \\
$\square$ Clinical data
\end{tabular}

\begin{tabular}{|c|c|}
\hline $\mathrm{n} / \mathrm{a}$ & Involved in the study \\
\hline$V$ & ChIP-seq \\
\hline Х & $\square$ Flow cytometry \\
\hline & MRI-based neuroimaging \\
\hline
\end{tabular}

\section{Antibodies}

The following primary antibodies have been used in immunofluorescence: Goat anti-Doublecortin (DCX), Santa Cruz Biotechnology, RRID:AB_2088494, 1:1000; Mouse anti-Doublecortin (DCX), Santa Cruz Biotechnology, RRID:AB_10610966, 1:50; Rabbit anti-Doublecortin (DCX), kindly provided by Dr. Gleeson (University of California), 1:200; Rabbit anti-Doublecortin (DCX), Atlas Antibodies, RRID:AB_2674950, 1:50; Mouse anti-PSA-NCAM, Millipore, RRID:AB_9521, 1:1000; Rabbit anti-Calretinin, Swant, RRID:AB_261971, 1:500; Rabbit anti-Calbindin, Swant, RRID:AB_272122, 1:500; Rabbit anti-Phospho-Histone3, RRID:AB_310177, 1:500; Rabbit anti-Prox1, Reliatech, RRID:AB_10013821, 1:500; Rabbit anti-NeuN, Millipore, RRID:AB_10807945, 1:1000; Mouse anti-4R-Tau, Millipore, RRID:AB_310014, 1:500; Rabbit anti-total Tau, Synaptic Systems, RRID:AB_114719, 1:500; Mouse anti-Betall Tubulin, Promega, RRID:AB_430874, 1:1000; Mouse anti-GFAP, Millipore, RRID:AB_2294571, 1:1000; Rabbit anti-Phospho-Tau(S396), Thermo Fisher, RRID:AB_253374, 1:500; Mouse anti-Beta-Amyloid, Covance, RRID:AB_2564682, 1:1000.

The following secondary antibodies were used to detect the binding of primary antibodies: Donkey Alexa-555 anti-goat, Thermo Fisher, A-21432, 1:1000; Donkey Alexa-488 anti-goat, Thermo Fisher, A-110552, 1:1000; Donkey Alexa-488 anti-rabbit, Thermo Fisher, A-21206, 1:1000; Donkey Alexa-647 anti-rabbit, Thermo Fisher, A-31573, 1:1000; Donkey Alexa-555 anti-rabbit, Thermo Fisher, A-31572, 1:1000; Donkey Alexa-488 anti-mouse, Thermo Fisher, A-21202, 1:1000; Donkey Alexa-647 anti-mouse, Thermo Fisher, A-31571, 1:1000; Donkey Alexa-555 anti-mouse, Thermo Fisher, A-31570, 1:1000.

Validation
- Goat anti-Doublecortin (DCX), Santa Cruz Biotechnology, RRID: AB_2088494: Validated by manufacturer to detect DCX of mouse, rat, human, and avian origin by WB, IP, IF, IHC, and ELISA. We further validated this antibody by pre-adsorption with a specific blocking peptide (Abcam, Cat \# ab19804). This validation was performed by dot blot and IHC.

- Mouse anti-Doublecortin (DCX), Santa Cruz Biotechnology, RRID:AB_10610966: Validated by manufacturer to detect DCX of mouse, rat, and human origin by WB, IP, IF, IHC, and ELISA.

- Rabbit anti-Doublecortin (DCX), kindly provided by Dr. Gleeson (University of California): Validated by Dr. Gleeson's lab to detect DCX of mouse and human origin.

- Rabbit anti-Doublecortin (DCX), Atlas Antibodies, RRID:AB_2674950: Validated by manufacturer to detect DCX of human origin by IHC.

- Mouse anti-PSA-NCAM, Millipore, RRID:AB_9521: Validated by manufacturer to detect PSA-NCAM of human, rat, and mouse origin by ICC, IHC, RIA, and WB. 
- Rabbit anti-Calretinin, Swant, RRID:AB_261971: Validated by manufacturer to detect Calretinin of human, monkey, rat, mouse,
guinea pig, chicken, and fish origin by WB and IHC.

- Rabbit anti-Calbindin, Swant, RRID:AB_272122: Validated by manufacturer to detect Calbindin of human, monkey, rat, mouse, chicken, and fish origin by WB and IHC.

- Rabbit anti-Phospho-Histone3, RRID:AB_310177: Validated by manufacturer to detect phosphorylated histone 3 of mouse and human origin by ICC, IP, and WB.

- Rabbit anti-Prox1, Reliatech, RRID:AB_10013821: Validated by manufacturer to detect Prox1 of human origin by IF and WB.

- Rabbit anti-NeuN, Millipore, RRID:AB_10807945: Validated by manufacturer to detect NeuN of human, mouse, rat, and snail origin by ICC, IHC, IF, and WB.

- Mouse anti-4R-Tau, Millipore, RRID:AB_3100: Validated by manufacturer to detect 4R-Tau of human, rabbit, bovine, and mouse origin by IHC and WB.

- Rabbit anti-total Tau, Synaptic Systems, RRID:AB_114719: Validated by manufacturer to detect Tau of rat, mouse, and human origin by WB, IP, ICC, and IHC.

- Mouse anti-Beta-III-Tubulin, Promega, RRID:AB_430874: Validated by manufacturer to detect Beta-III-Tubulin of most mammalian species, specifically rat and human, by ICC, IHC, and WB.

- Mouse anti-GFAP, Millipore, RRID:AB_2294571: Validated by manufacturer to detect GFAP of chicken, human, porcine, and rat origin by IP, IHC, and WB.

Secondary antibodies were validated by manufacturer and have been extensively validated in the literature.

\section{Human research participants}

Policy information about studies involving human research participants

Population characteristics A total number of 13 neurologically healthy control subjects were included in the present study. Extended Table 3 includes detailed epidemiological data of these subjects, including gender and age.

Tau phosphorylation (AT100 epitope) in the anterior hippocampus, prefrontal, parietal and temporal associative isocortex, and in the primary visual cortex was quantified at the neuropathology unit of the Banco de Tejidos CIEN to determine that all these subjects were at Braak-Tau stage 0 , following previously described protocols.

In all cases, brain tissue donation, processing, and use for research were in compliance with published protocols, which include the obtaining of informed consent for brain tissue donation from living donors, and the approval of the whole donation process by the Ethical Committee.

Recruitment

Subjects were recruited on the basis of the brain tissue donation program coordinated by the neuropathology unit of the Banco de Tejidos CIEN. There are no potential self-selection bias that may be likely to impact results. Written informed consent was obtained from all donors, and the whole donation process was approved by the Ethical Committee of the Banco de Tejidos CIEN.

Ethics oversight

Ethical Committee of the Banco de Tejidos CIEN (Committee Approval Reference \#15-20130110\#).

Note that full information on the approval of the study protocol must also be provided in the manuscript. 